\title{
Calcium Channel Agonists Protect against Neuromuscular Dysfunction in a Genetic Model of TDP-43 Mutation in ALS
}

\author{
Gary A.B. Armstrong and Pierre Drapeau \\ Department of Pathology and Cell Biology and Groupe de Recherche sur le Système Nerveux Central, Université de Montréal, Montréal, QC, H3C 3J7, \\ Canada
}

TAR DNA binding protein (TDP-43, encoded by the TARDBP gene) has recently been shown to be associated with amyotrophic lateral sclerosis (ALS), but the early pathophysiological deficits causing impairment in motor function are unknown. Here we expressed the wild-type human gene (wtTARDBP) or the ALS mutation G348C (mutTARDBP) in zebrafish larvae and characterized their motor (swimming) activity and the structure and function of their neuromuscular junctions (NMJs). Of these groups only mutTARDBP larvae showed impaired swimming and increased motoneuron vulnerability with reduced synaptic fidelity, reduced quantal transmission, and more orphaned presynaptic and postsynaptic structures at the NMJ. Remarkably, all behavioral and cellular features were stabilized by chronic treatment with either of the L-type calcium channel agonists FPL 64176 or Bay K 8644 . These results indicate that expression of mutTARDBP results in defective NMJs and that calcium channel agonists could be novel therapeutics for ALS.

\section{Introduction}

Amyotrophic lateral sclerosis (ALS) is a devastating neurodegenerative disorder that manifests clinically in adulthood and is characterized by the selective loss of motoneurons in the cerebral cortex and spinal cord (Pasinelli and Brown, 2006). ALS is untreatable and death usually occurs within $2-5$ years following clinical diagnosis. Though most ALS cases are sporadic (SALS), familial ALS (FALS) with a clear Mendelian inheritance and high penetrance occurs in $\sim 10 \%$ of cases and is clinically indistinguishable from SALS (Pasinelli and Brown, 2006). Considerable progress has been made in recent years in describing the underlying genetic basis of ALS, notably mutations in the genes for TDP-43 (TARDBP) (Kabashi et al., 2008; Sreedharan et al., 2008) and fused in sarcoma (FUS) (Kwiatkowski et al., 2009; Vance et al., 2009). Yet despite these and other advancements a thorough understanding of their resulting pathophysiology remains elusive, particularly at early and clinically important stages, but is of paramount importance for clarification of the neurodegenerative mechanisms and elucidation of therapeutic approaches.

It is now widely recognized that early and significant changes occur at the neuromuscular junction (NMJ) long before clinical presentation of ALS. Appreciation for the importance of preclin-

\footnotetext{
Received Aug. 21, 2012; revised Nov. 26, 2012; accepted Nov. 28, 2012.

Author contributions: G.A.B.A. and P.D. designed research; G.A.B.A. performed research; G.A.B.A. analyzed data; G.A.B.A. and P.D. wrote the paper.

This work was funded by Natural Sciences and Engineering Research Council of Canada (G.A.B.A.), Canada Research Chairs program, FRQS, Canadian Institutes of Health Research, and the Frick Foundation (P.D.). We thank R.M. Robertson and S.A. Patten for critical feedback on earlier versions of this manuscript; G. Laliberté and M. Drits for help with animal care; and M. Liao, L.D. Knogler, V. Bercier, and A. Lissouba for technical assistance.

Correspondence should be addressed to Gary A.B. Armstrong, Department of Pathology and Cell Biology and Groupe de Recherche sur le Système Nerveux Central, Université de Montréal, Montréal, QC, H3C 3J7, Canada. E-mail: gary.ab.armstrong@gmail.com.

DOI:10.1523/JNEUROSCI.4003-12.2013

Copyright $\odot 2013$ the authors $\quad 0270-6474 / 13 / 331741-12 \$ 15.00 / 0$
}

ical disease-associated abnormalities has largely been garnered from studies of mutant super oxide dismutase 1 (SOD1 ${ }^{\mathrm{G} 93 \mathrm{~A}}$ ) using mouse models of ALS in which an early retraction or "dieback" of presynaptic motor endings was observed long before the death of motoneurons (for review, see Murray et al., 2010; Dadon-Nachum et al., 2011). Unlike the pathologies occurring from mutant SOD1 expression, little is known about the pathophysiology following mutant TDP-43 expression though increased NMJ denervation (possibly die-back) has been reported recently in rat and mouse models (Zhou et al., 2010; Swarup et al., 2011). Important unanswered questions remain, in particular are there convergent molecular and physiological pathways between mutant SOD1 pathogenesis and proteinopathies associated with TDP-43 that could be a rich target for treatments? This could be particularly interesting if preclinical functional deficits could be corrected.

To address these pathophysiological questions we used a larval zebrafish model previously described by our laboratory (Kabashi et al., 2010b) and addressed the consequences of human TDP-43 expression on motoneuron function. Zebrafish larvae expressing mutTARDBP (but not wtTARDBP) or mutations in other motoneuron disease-related genes, including SOD1, ALS2, FUS, GRN, or SMN1, show symptoms reminiscent of these diseases, such as disruption of motoneuron projections resembling die-back and re-innervation of motor axons and consequent motor deficits (for review, see Kabashi et al., 2010a). Zebrafish have thus been useful for advancing our understanding of disease genetics (Lemmens et al., 2007; Boon et al., 2009; Kabashi et al., 2010b, 2011; Ramesh et al., 2010). As zebrafish are also amenable to neurophysiological analyses (Buss and Drapeau, 2002), in this study we characterized functional abnormalities arising at the NMJ in zebrafish expressing mutTARDBP compared with wtTARDBP. Based on the physiological insights we devised pharmacological methods to test for the recovery of functional 
synaptic transmission at the $\mathrm{NMJ}$ and restoration of locomotor behavior.

\section{Materials and Methods}

Zebrafish lines. Wild-type zebrafish (Danio rerio) were bred and maintained according to standard procedures (Westerfield, 1995). All experiments were performed in compliance with the guidelines of the Canadian Council for Animal Care and conducted at the Université de Montréal. All experiments were performed on sexually undifferentiated zebrafish larvae $52-56 \mathrm{~h}$ postfertilization (hpf).

Preparation and injection of TARDBP. Human TARDBP cDNA was obtained from Open Biosystems. G348C mutation was introduced using site-directed mutagenesis in the appropriate vector using QuikChange XL Site-Directed Mutagenesis Kit (Stratagene) as previously described (Kabashi et al., 2010b). cDNA constructs encoding N-FLAG and C-Myc were incorporated and subcloned into pCS2+ plasmid vectors, which were subsequently used to generate mRNA.

Injections in 1-2 cell stage blastulae were performed as previously described (Kabashi et al., 2010b). Briefly, wtTARDBP and mutTARDBP (G348C) mRNAs were transcribed from NotI-linearized pCS2+ using SP6 polymerase with the mMESSAGE Machine Kit (Ambion). The mRNA was diluted in nuclease-free water (Ambion) with $0.05 \%$ Fast Green (Sigma) to a final concentration of $25 \mathrm{ng} / \mu \mathrm{l}$ and backfilled in a pulled (Sutter Instrument) thin-walled borosilicate capillary tube and pressure injected into the cell using a PicoSpritzer III (General Valve). Unlike stable expression of zebrafish TARDBP mRNA (measured by qRT-PCR), human wtTARDBP or mutTARDBP mRNA were undetectable at $54 \mathrm{hpf}$, suggesting that the mRNA had degraded by this time; protein levels of wt and mut TDP-43 were comparable, as previously reported (Kabashi et al., 2010b). In that study we determined that expression of wtTARDBP following injection of $25 \mathrm{ng} / \mu \mathrm{l}$ mRNA was sufficiently high to rescue the loss-of-function phenotype (following knockdown of the zebrafish gene) while not high enough to cause a nonspecific phenotype upon injection of wt TARDBP mRNA alone. No obvious gross anatomical disparity in larval body was observed across treatments at $54 \mathrm{hpf}$. Nor was there any apparent delay in development as migration of the lateral line primordium (used for staging development; Kimmel et al., 1995) was unaffected by exogenous mRNA expression.

Pharmacology. All chemicals were obtained from Sigma-Aldrich (unless otherwise stated) and dissolved in Evan's solution (see below), using a minimum amount of dimethylsulfoxide (DMSO) if required $(0.1 \%)$ and bath applied to semi-intact preparations. For drug applications to intact freely behaving animals chemicals were dissolved in egg water. Acute (30 min; 1 and $10 \mu \mathrm{M}$ ) and chronic ( $12 \mathrm{~h} ; 0.1$ and $1 \mu \mathrm{M}$ ) exposures to FPL 64176 (Tocris Bioscience; L-type voltage-dependent calcium channel agonist), 1 and $10 \mu \mathrm{M}$ Bay K 8644 (Tocris Bioscience; L-type voltage-dependent calcium channel agonist) $(1 \mu \mathrm{M})$, nifedipine (Tocris Bioscience; L-type voltage-dependent calcium channel antagonist), or $(0.1,1,5,10$ and $50 \mu \mathrm{M})$ roscovitine (P/Q-type voltage-dependent calcium channel agonist) were applied in the dark as they are light sensitive. Larvae chronically treated with these compounds were rinsed with fresh egg water $4 \mathrm{~h}$ before examination of locomotor activity.

Free-swimming restrained tail-beat behavior. Assessment of zebrafish locomotor patterns was performed at room temperature $\left(22-25^{\circ} \mathrm{C}\right)$. Larvae were placed in the middle of a circular arena ( $150 \mathrm{~mm}$ diameter) filled with aquarium water. Burst swimming was initiated by a single touch to the tail and locomotor activity was recorded from above digitally at $30 \mathrm{~Hz}$ (Grasshopper 2 camera; Point Gray Research). Swim duration, swim distance, and maximum swim velocity were quantified off-line using the manual tracking plug-in for ImageJ.

Muscle whole-cell voltage-clamp recordings. As described previously (Buss and Drapeau, 2002), zebrafish were anesthetized in 0.04\% tricaine (Sigma) dissolved in modified Evans solution containing the following (in mM[sCAP]): $134 \mathrm{NaCl}, 2.9 \mathrm{KCl}, 2.1 \mathrm{CaCl}_{2}, 1.2 \mathrm{MgCl}_{2}, 10 \mathrm{HEPES}$, and 10 glucose, adjusted to $290 \mathrm{mOsm}, \mathrm{pH}$ 7.8. The zebrafish were then pinned with fine ( 0.001 inch) tungsten wires through their notochords to a Sylgard-lined dish. The outer layer of skin between the pins was removed using a fine glass electrode and forceps exposing the musculature.
The preparation was then visualized by oblique illumination (Olympus BX61W1).

Standard whole-cell voltage-clamp recordings were obtained from fast-twitch (embryonic white) muscle cells (Buss and Drapeau, 2002). In these recordings $20 \mu \mathrm{M} \mathrm{N}$-benzyl-p-toluenesulfonamide, an inhibitor of myosin ATPase, dissolved in $0.1 \%$ DMSO was added to the saline to minimize muscle contractions. Glass electrodes (3-4 M $\Omega$ ) were pulled from thin-walled Kimax-51 borosilicate glass (Kimble Chase) and filled with the following intracellular solution containing (in mM): $130 \mathrm{CsCl}, 2$ $\mathrm{MgCl}_{2}, 10 \mathrm{HEPES}$, and 10 EGTA adjusted to $\mathrm{pH}$ 7.2, $290 \mathrm{mOsm}$. Cells were held near their resting potential at $-65 \mathrm{mV}$ and series resistance was $<8 \mathrm{M} \Omega$ compensated to $70-90 \%$. In some experiments $1 \mu \mathrm{M}$ tetrodotoxin was perfused over the preparation to isolate spontaneous (quantal) miniature endplate currents ( $\mathrm{mEPC}$ ). All electrophysiological data were sampled at $40 \mathrm{kHz}$ using an Axopatch 200B amplifier (Molecular Devices) and digitized using a Digidata 1440A (Molecular Devices) and stored on a computer for later analysis using pCLAMP 10 software (Molecular Devices).

Paired motoneuron/muscle recordings. Paired motoneuron/muscle recordings were performed following procedures previously described (Wen and Brehm, 2005). Briefly, paired motor motoneuron/muscle recordings were obtained by perfusing collagenase $(1 \mathrm{mg} / \mathrm{ml})$ over the preparation for $10 \mathrm{~min}$. This allowed for partial digestion before red and white muscle cells overlying the spinal cord were removed by aspiration to expose the spinal cord while leaving the ventral root and deeper muscle cells intact. Somites 13-16 were selected for recording. Patch-clamp electrodes (7-9 M $\Omega$ ) were filled with the following intracellular solution containing (in mM): 105 D-gluconic acid, $16 \mathrm{KCl}, 2 \mathrm{MgCl}_{2}, 10 \mathrm{HEPES}$, and 10 EGTA adjusted to $\mathrm{pH} 7.2,290 \mathrm{mOsm}$. The caudal and primary (CaP) motoneuron was selected because of its size and projection pattern to intact ventral regions of the trunk musculature. Motoneuron action potentials were elicited by a train of $200 \mathrm{pA}, 2 \mathrm{~ms}$ current steps into the motoneuron soma in current-clamp mode at $10 \mathrm{~Hz}$ or $30 \mathrm{~Hz}$ for $10 \mathrm{~s}$. Muscle recordings were the same as described above except $1 \mu \mathrm{M}$ QX-314 was added to the patch pipette solution to block voltage-gated sodium currents and muscle contractions.

Acridine orange staining. Zebrafish were incubated in $1 \mu \mathrm{g} / \mathrm{ml}$ acridine orange $(\mathrm{AO})$ for $30 \mathrm{~min}$ then repeatedly washed in aquarium water. Larvae were anesthetized in tricaine before being visualized under a $10 \times$ water-immersion lens mounted on a Quorum Technologies spinning disk confocal microscope with a CSU10B (Yokogawa) spinning head mounted on an Olympus BX61W1 fluorescence microscope and connected to a Hamamatsu ORCA-ER camera. Spinal cords were examined under a 470-490 nM excitation filter and images were acquired using Volocity software (Improvision). The number of neurons per five somites was counted per embryo from a set of stacked $Z$-series images. AO stained spinal cord images are presented in pseudocolor.

Immunohistochemistry. Animals were fixed in $4 \%$ paraformaldehyde overnight at $4^{\circ} \mathrm{C}$. After fixation the larvae were rinsed several times $(1 \mathrm{~h})$ with PBS and then incubated in PBS containing $1 \mathrm{mg} / \mathrm{ml}$ collagenase (20 $\mathrm{min})$ to remove skin. The collagenase was washed off with PBS $(1 \mathrm{~h})$ and the larvae were incubated in PBS with Triton X-100 (PBST) containing $10 \mathrm{mg} / \mathrm{ml}$ sulforhodamine-conjugated $\alpha$-bungarotoxin ( $\alpha$ BTX; $30 \mathrm{~min}$ ). The larvae were then rinsed several times with PBST (30 min) and then incubated in freshly prepared block solution containing primary antibody against synaptic vesicle 2 (SV2; 1:200; Molecular Probes) or ZNP-1 (1:100; Molecular Probes) overnight at $4^{\circ} \mathrm{C}$. Following this, larvae were incubated in block solution containing a secondary antibody (Alexa Fluor 488, 1:1000; Invitrogen) for $6 \mathrm{~h}$ at $4^{\circ} \mathrm{C}$ before being mountain on a glass slide in 70\% glycerol. The NMJs were visualized using a Quorum Technologies spinning disk confocal microscope with a CSU10B (Yokogawa) spinning head mounted on an Olympus BX61W1 fluorescence microscope and connected to a Hamamatsu ORCA-ER camera. Images were acquired using Volocity software (Improvision).

Statistical analysis. SigmaPlot 11.0 integrated with SigmaStat 3.1 was used to assess data groupings for significance. Statistical analyses used one-way repeated-measures ANOVA, followed by a post hoc Tukey multiple-comparison test. For nonparametric tests a Kruskal-Wallis 
A

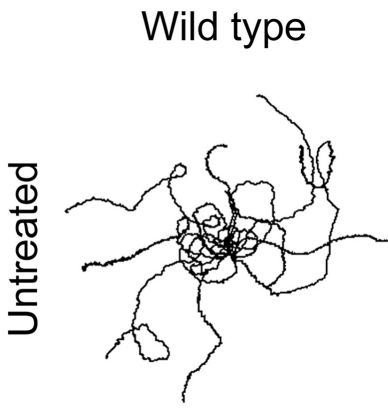

$$
\text { wtTARDBP }
$$

mutTARDBP

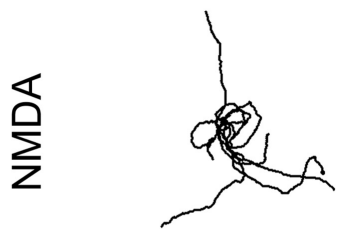

B
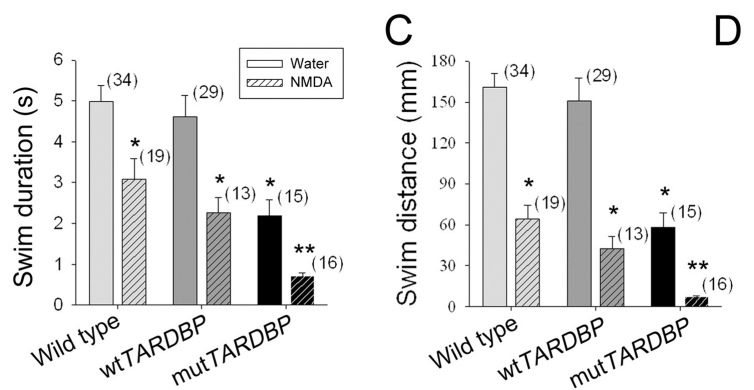

$\mathrm{E}$
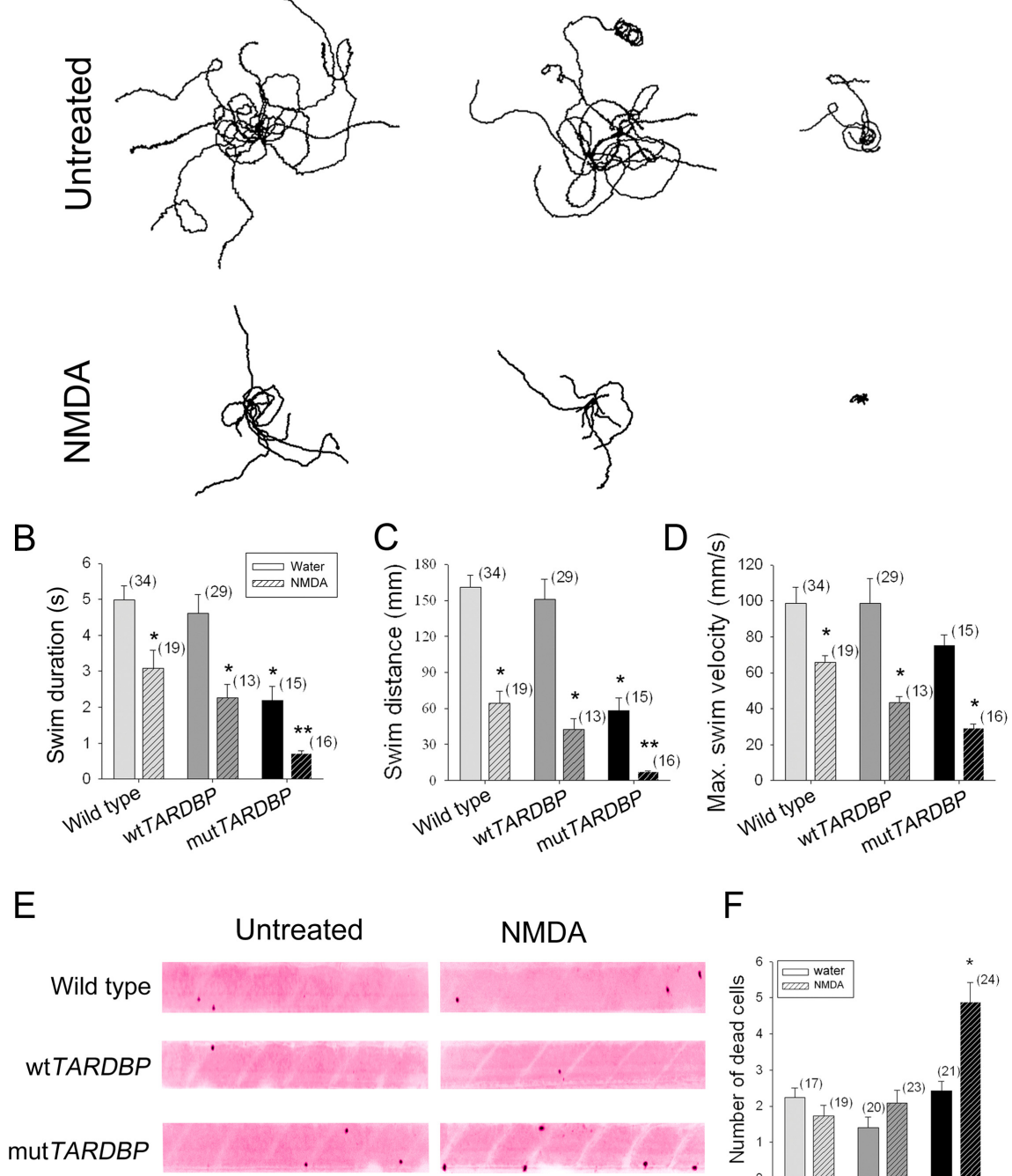

$\mathrm{F}$

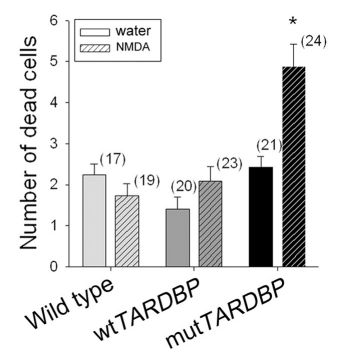

Figure 1. Zebrafish expressing mutTARDBP displayed impaired locomotion and NMDA application increased the number of dead neurons in the spinal cord. Locomotor behavior was reliably evoked by a light touch to the tail. $A$, Examples of 10 superimposed locomotor path traces from each treatment group starting at the center. Swim duration $(\boldsymbol{B})$, swim distance $(\boldsymbol{C})$, and maximum swim velocity $(\boldsymbol{D})$ were calculated for individual fish. Animals expressing mutTARDBP displayed significant impairments in locomotor behavior when compared with wild-type larvae and larvae expressing wTTARDBP. NMDA application (200 $\mu \mathrm{M})$ exacerbated locomotor performance in all groups. We observed an increase in the number of dead cells (revealed by A0 staining) following NMDA application in mutTARDBP larvae only. $\boldsymbol{E}$, Representative spinal cord images of A0-positive cells. $\boldsymbol{F}$, Number of A0-positive cells per five somites. Numbers in parentheses represent sample sizes. Single asterisk represent statistical significant differences from wild-type zebrafish $\left({ }^{*} p<0.05\right)$ and double asterisks represent $\left({ }^{* *} p<0.01\right)$.

one-way ANOVA on ranks was performed. Significance was assessed at ${ }^{\star} p<0.05$ or ${ }^{* *} p<0.01$.

\section{Results}

\section{MutTARDBP expression impairs locomotor function and is} exacerbated by NMDA

Zebrafish expressing missense mutations such as the ALScausing G348C mutation of human TARDBP (mutTARDBP) were shown previously to have impairments in locomotor function with shortened and hyperbranched motoneuron axons and impaired touch-evoked swimming behavior by hatching at 54 hpf (Kabashi et al., 2010b, 2011). Two-day-old wild-type zebrafish $(91.1 \%, 676 / 742)$ and zebrafish expressing wtTARDBP

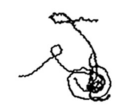

$(78.2 \%, 472 / 603)$ displayed a robust normal escape response (Buss and Drapeau, 2001). This was characterized by vigorous anguilliform undulations of the body axis that propelled the larva forward for a few seconds. In contrast, larvae expressing mutTARDBP, though capable of responding to touch and thus indicating an intact sensory system, generally were able to elicit a bout of swimming but fatigued quickly. They displayed an abnormal motor phenotype $(68.0 \%, 564 / 830)$ characterized by a slow and short escape response following touch. In some cases we observed these larvae continuing to beat their tails but this was insufficient to propel them.

To more carefully quantify motor behavior, we performed high-speed video analyses of touch-evoked locomotor behavior. MutTARDBP larvae displayed a shorter swim duration following touch $(p<0.001$; Fig. $1 A, B)$, swam shorter distances $(p<0.001$; Fig. $1 C)$, and had reduced maximum swim velocities $(p<$ 0.001 ; Fig. $1 D)$ compared with wt$T A R D B P$ and wild-type larvae. In an initial attempt to improve swim performance in animals expressing mutTARDBP we treated animals with NMDA and examined locomotor ability, as NMDA is known to evoke motor activity in 3-d-old zebrafish (McDearmid and Drapeau, 2006). However, we observed impairment in locomotor behavior following NMDA treatment $(200 \mu \mathrm{M}$ for $2 \mathrm{~h})$ in all groups and zebrafish expressing mutTARDBP were more severely affected (Fig. $1 A-D$ ). This motor deficit in mutTARDBP was coincident with an increase in the number of dead cells detected by AO staining in the spinal cord in larvae treated with NMDA. Dead cells were identified throughout the spinal cord including the ventralmost region containing motor neurons (Fig. 1E); however, an increase in cell death was not evident in larvae expressing wtTARDBP or in untreated wild-type larvae (Fig. $1 E, F)$. Animals not treated with NMDA did not display any significant differences in the number of dead neurons in the spinal cord across the three treatment groups, indicating that NMDA increased toxicity selectively in mutTARDBP larvae.

\section{MutTARDBP expression does not alter muscle} electrophysiological properties

Injection of mRNA at the 1-2 cell stage results in ubiquitous expression of TARDBP throughout the zebrafish by $48 \mathrm{hpf}$. Thus, poor locomotor performance in zebrafish expressing mutTARDBP might result in deficits originating within or outside the nervous system. To investigate the latter possibility we examined the electrophysiological properties of fast-twitch muscle cells 


\begin{tabular}{|c|c|c|c|}
\hline & Wild type & wtTARDBP & mutTARDBP \\
\hline \multicolumn{4}{|l|}{ Fast-twitch muscle } \\
\hline $\mathrm{Vm}(\mathrm{mV})$ & $-68.2 \pm 2.3(15)$ & $-67.1 \pm 4.8(10)$ & $-66.3 \pm 2.1(15)$ \\
\hline $\mathrm{Cm}(\mathrm{pF})$ & $38.6 \pm 5.2(15)$ & $38.7 \pm 3.1(10)$ & $37.6 \pm 4.3(15)$ \\
\hline $\operatorname{Rm}(M \Omega)$ & $152.7 \pm 23.3(15)$ & $156.7 \pm 27.1(10)$ & $164.1 \pm 45.1(15)$ \\
\hline Tetanus frequency (Hz) & $41.0 \pm 1.3(10)$ & $40.8 \pm 1.3(10)$ & $40.4 \pm 1.2(10)$ \\
\hline \multicolumn{4}{|l|}{$\mathrm{CaP}$ (primary motoneuron) } \\
\hline $\mathrm{Vm}(\mathrm{mV})$ & $-64.1 \pm 1.2(16)$ & $-62.0 \pm 1.4(10)$ & $-64.4 \pm 0.9(15)$ \\
\hline $\mathrm{Cm}(\mathrm{pF})$ & $6.8 \pm 0.6(16)$ & $6.5 \pm 0.8(10)$ & $5.6 \pm 0.9(15)$ \\
\hline $\operatorname{Rm}(M \Omega)$ & $263.8 \pm 33.9(16)$ & $263.5 \pm 26.6(10)$ & $242.6 \pm 20.8(15)$ \\
\hline Rheobase (pA) & $86.6 \pm 5.1(10)$ & $86.2 \pm 8.7(10)$ & $65.3 \pm 6.1(15)^{*}$ \\
\hline $\begin{array}{l}\text { AP frequency }(\mathrm{Hz}) \\
\text { @ } 20 \text { pA injection }\end{array}$ & $0(17)$ & $0(7)$ & $0(20)$ \\
\hline $\begin{array}{l}\text { AP frequency }(\mathrm{Hz}) \\
\quad @ 40 \mathrm{pA} \text { injection }\end{array}$ & $0(17)$ & $0(7)$ & $10.6 \pm 7.6(20)^{*}$ \\
\hline $\begin{array}{l}\text { AP frequency }(\mathrm{Hz}) \\
\quad @ 60 \mathrm{pA} \text { injection }\end{array}$ & $0(17)$ & $0(7)$ & $38.3 \pm 13.4(20)^{*}$ \\
\hline $\begin{array}{l}\text { AP frequency }(\mathrm{Hz}) \\
\quad @ 80 \mathrm{pA} \text { injection }\end{array}$ & $26.3 \pm 10.2(17)$ & $25.7 \pm 16.7(7)$ & $60.3 \pm 14.9(20)^{3}$ \\
\hline Threshold (mV) & $-32.5 \pm 1.4(10)$ & $-31.5 \pm 1.8(10)$ & $-35.4 \pm 1.3(15)$ \\
\hline
\end{tabular}

AP, action potential. Asterisks represent statistical significant differences from wild-type zebrafish.

(Table 1). We observed first that fast-twitch muscle cells, regardless of expression of mutTARDBP or wtTARDBP, maintained a similar resting membrane potential to wild-type zebrafish. Second, whole-cell capacitance and membrane resistance were not found to be different indicating that the surface area and passive conductance were not affected by expression of mutTARDBP. Third, the frequency at which the fast-twitch muscle entered tetanus was unaffected by expression of wtTARDBP or mut$T A R D B P$, indicating normal function. Having found no physiological abnormalities specifically with fast-twitch muscles we turned to examining the primary motoneurons innervating the muscles.

\section{Increased motoneuron excitability with defective NMJ transmission in mutTARDBP}

The larval zebrafish offers considerable advantages for investigating motoneuron physiology as identifiable cells are found within the spinal cord. Each hemisomite has one CaP motoneuron that is easily identified by its large cell body and its axonal projection, which innervates ventral trunk musculature (Westerfield et al., 1986). Whole-cell recordings of CaP motoneurons in wild-type, wtTARDBP, and mutTARDBP larvae did not yield any differences in membrane potential, cell capacitance, input resistance, or action potential threshold (Table 1). However, we did find that $\mathrm{CaP}$ motoneurons in zebrafish expressing mutTARDBP displayed reduced rheobase current $(p<0.048)$ and generated higher frequencies of action potentials following current injection $(p<0.05$; Table 1$)$ indicating that these cells were more excitable than those in wild-type and wtTARDBP larvae. Together, both muscle and $\mathrm{CaP}$ motoneuron electrophysiological data indicate mostly normal electrophysiology despite severe impairments in locomotor function observed in fish expressing mutTARDBP.

Reduced fidelity of NMJ transmission in mutTARDBP larvae To resolve NMJ activity we performed paired CaP motoneuronfast-twitch muscle recordings and assessed synaptic transmission under biologically relevant conditions (Fig. 2A,B). To do this we started by stimulating a $\mathrm{CaP}$ motoneuron at $10 \mathrm{~Hz}$ for $10 \mathrm{~s}$, a frequency generally lower than CPG-driven rhythmic input to muscles during swimming at this stage (Buss and Drapeau, 2001). We did not find any differences in the fidelity of synaptic transmission as success rates among the three treatment groups were robust (Fig. 2C, E, G,I). We next stimulated the motoneuron at 30 $\mathrm{Hz}$ for $10 \mathrm{~s}$ (Fig. 2D,F,H), a frequency similar to that of the locomotor CPG. We confirmed a previous report (Wen and Brehm, 2005) demonstrating that the majority of ventral trunk muscles are faithfully innervated by the CaP motoneuron, but a small proportion $(<5 \%)$ of action potentials fails to generate a corresponding EPC, suggesting occasional lack of vesicular release, even though asynchronous release was observed following stimulation (Fig. 2D, arrow). Similar observations were made for larvae expressing wtTARDBP (Fig. $2 F$ ). In contrast, $30 \mathrm{~Hz}$ stimulation in zebrafish expressing mutTARDBP displayed a significantly reduced synaptic transmission success rate when compared with wild-type larvae $(p<0.028$; Fig. $2 H, I)$. In addition to a reduction in the fidelity of synaptic transmission, mean EPC amplitude in mutTARDBP larvae was significantly reduced during both $10(p<0.050)$ and $30 \mathrm{~Hz}$ stimulations $(p<0.020$; Fig. $2 J)$, EPC amplitude was more variable $(10 \mathrm{~Hz}, p<0.043 ; 30 \mathrm{~Hz}, p<$ 0.033; Fig. $2 \mathrm{~K}$ ), and poststimulus asynchronous release was not observed (Fig. $2 H$ ). These data suggest a strong presynaptic deficit in mutTARDBP larvae, which results in reduced fidelity of synaptic transmission across the NMJ and possibly a reduction in quantal content and/or an attenuated postsynaptic response.

\section{Abnormal NMJ structure and quantal events in mutTARDBP}

We have previously demonstrated disorganized and excessive branching of ventral motoneuron projections following mutTARDBP expression (Kabashi et al., 2010b). However, structural components of the NMJ have not been investigated. Double labeling of SV2 (a component of synaptic vesicles) and $\alpha$ BTX (which binds irreversibly to acetylcholine receptors) was performed. Normal NMJs have a tight juxtaposition of these presynaptic and postsynaptic components (Boon et al., 2009) and this was observed in wild-type zebrafish and fish expressing wt$T A R D B P$, wherein these animals displayed few orphaned $\alpha \mathrm{BTX}$ clusters (Fig. $3 A, B$ ) and few orphaned SV2 puncta (Fig. $3 A, C$ ). Conversely, zebrafish expressing mutTARDBP displayed a higher number of both orphaned $\alpha$ BTX clusters $(p<0.050)$ and SV2 puncta $(p<0.050)$ when compared with wild-type larvae and larvae expressing wtTARDBP (Fig. 3A-C).

Although we observed significant structural abnormalities at the NMJ of zebrafish expressing mutTARDBP, they do not necessarily demonstrate a specific functional deficit. To address this we examined mEPCs that occur naturally and spontaneously at healthy synapses and represent the unitary (quantal) event during synaptic transmission (Fig. 3D). The frequency of mEPCs in zebrafish expressing mutTARDBP was found to be reduced when compared with wild-type and wtTARDBP controls $(p<0.006$; Fig. $3 E)$, suggesting a reduction in the number of functional presynaptic endings. The mean amplitude of mEPCs occurring in zebrafish expressing mutTARDBP was also found to be smaller compared with wild-type zebrafish ( $p<0.014$; Fig. $3 D, F)$ while the kinetics (rise and decay times; Fig. $3 G, H)$ was not significantly different. A reduction in quantal size without a change in kinetics likely results from reduced acetylcholine receptor density at the postsynaptic membrane. We estimated the quantal content in paired $\mathrm{CaP}$ motoneuron-fasttwitch muscle recordings and found that at both 10 and $30 \mathrm{~Hz}$ stimulation, mutTARDBP larvae had a significantly reduced estimated quantal content when compared with both wild-type larvae and wtTARDBP larvae $(10 \mathrm{~Hz}, p<0.050 ; 30 \mathrm{~Hz}, p<0.016$; Fig. $3 I)$. These 
A

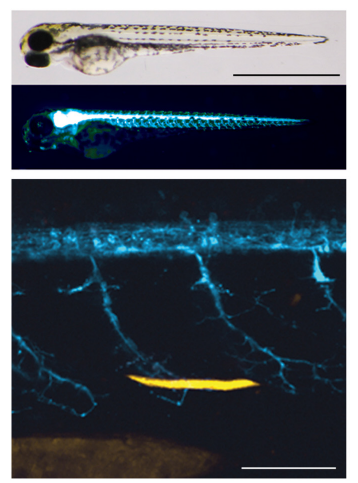

E

wtTARDBP $(10 \mathrm{~Hz})$

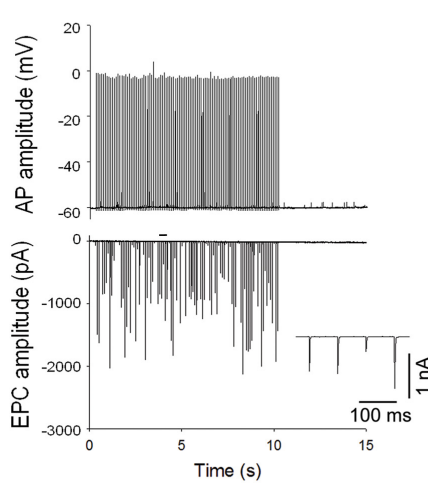

\section{I}

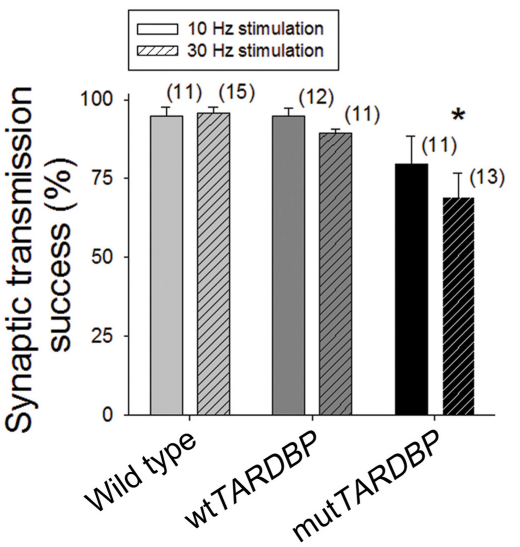

B

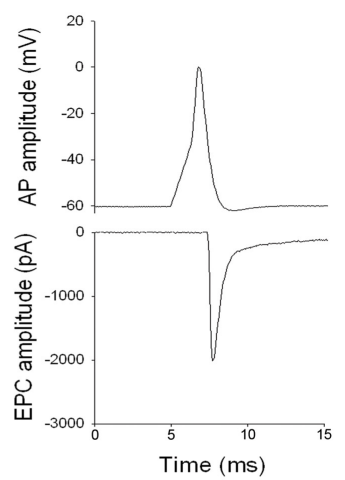

$\mathrm{F}$

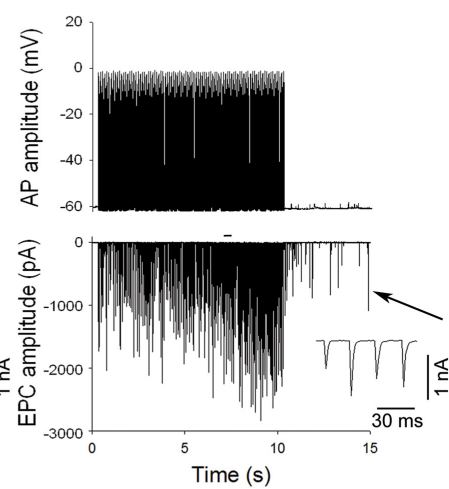

J
C Wild type $(10 \mathrm{~Hz})$

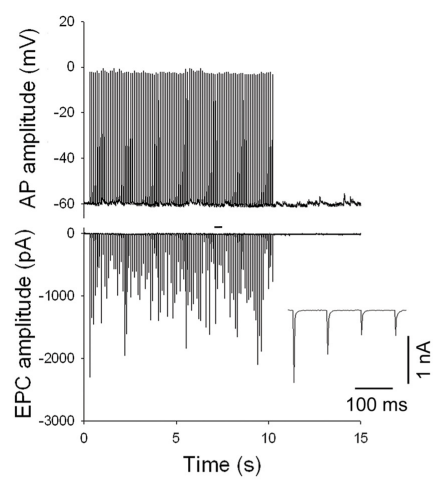

G

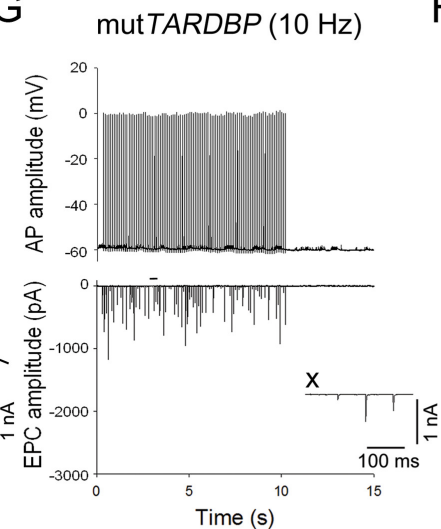

D Wild type $(30 \mathrm{~Hz})$

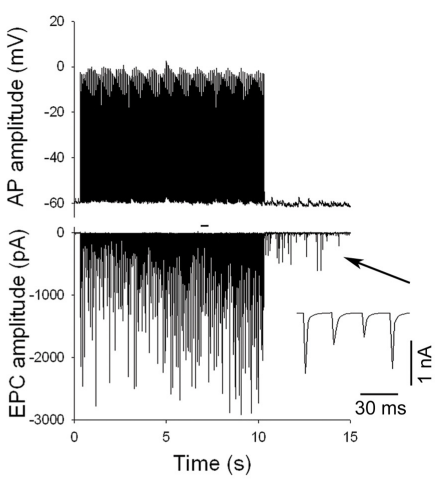

$\mathrm{H}$ mutTARDBP $(30 \mathrm{~Hz})$
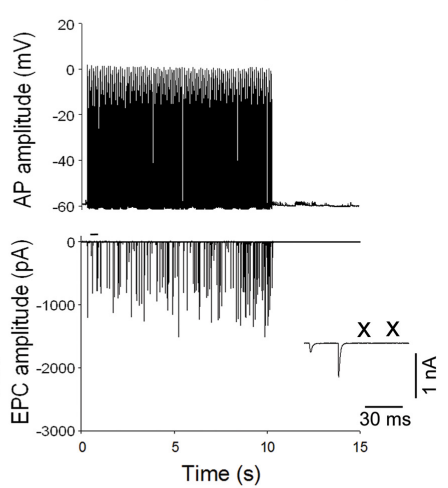<smiles>[AlH][V]</smiles>
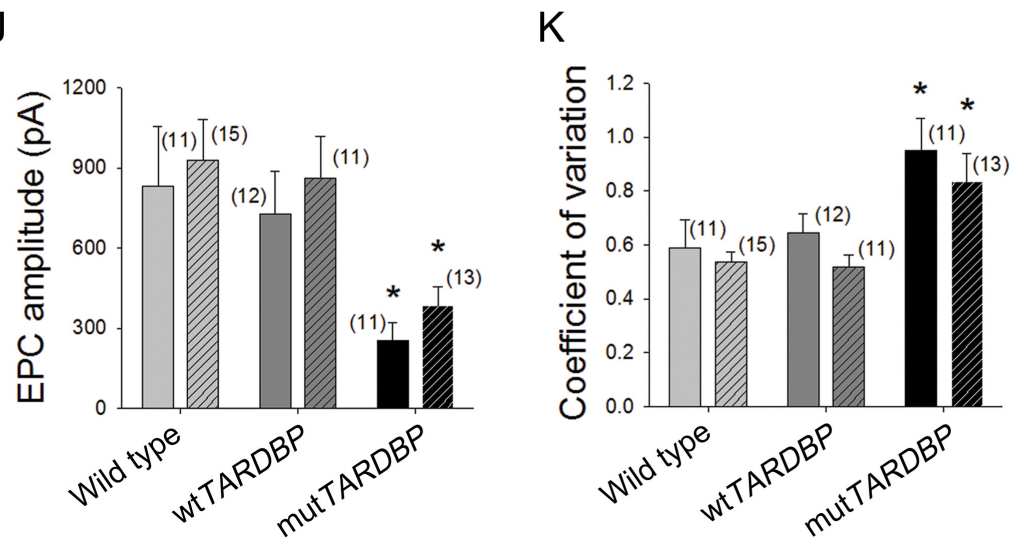

Figure 2. Zebrafish expressing mutTARDBP displayed a decrease in fidelity of NMJ synaptic transmission and attenuated EPC amplitude. $A$, Top, Transmitted light. Middle, fluorescent image of $H b 9$ promoter driving GFP (cyan) expression in motoneurons. Bottom, Somites with ventral roots and in yellow a single sulforhodamine-filled muscle cell. Paired (primary motoneuron/muscle) recordings were performed. $\boldsymbol{B}$, Example of whole-cell current-clamp trace of an action potential (AP) generated in the CaP motoneuron (top trace) and corresponding EPC measured in a fast-twitch muscle under whole-cell voltage-clamp (bottom trace). To assess synaptic transmission across the NMJ a 10 s train of depolarizing (AP generating) current steps was delivered at $10 \mathrm{~Hz}(\boldsymbol{C})$ or $30 \mathrm{~Hz}$ (D). Top traces show evoked APs and the bottom traces show corresponding fast-twitch muscle EPCsin a wild-type animal. Example traces of evoked $A P s$ and corresponding EPCsin a wtTARDBP at $10(\boldsymbol{E})$ and $30 \mathrm{~Hz}(\boldsymbol{F})$ and in a mut $T A R D B P$ larva at $10(\boldsymbol{G})$ and $30 \mathrm{~Hz}(\boldsymbol{H})$. Insets are corresponding enlarged example traces of EPCs denoted by the black dash above EPCs in $\boldsymbol{C} \boldsymbol{G}$ and $\boldsymbol{H}$. Arrows in $\boldsymbol{D}$ and $\boldsymbol{F}$ indicate poststimulus asynchronous EPCs. The $X$ in $\boldsymbol{G}$ and $\boldsymbol{H}$ indicates failure of release. I, mutTARDBP expressing larvae displayed a significant reduction in the fidelity of synaptic transmission at $30 \mathrm{~Hz}$, qualified by the failure of an AP to produce a corresponding EPC. Furthermore, the mean amplitude of EPCs in mutTARDBP expressing larvae was found to be significantly reduced at both 10 and $30 \mathrm{~Hz}$ stimulation frequencies $(J)$ and displayed a larger coefficient of variation at both stimulation frequencies $(\boldsymbol{K})$. Numbers in parentheses represent sample sizes. Asterisks represent statistical significant differences from wild-type zebrafish.

data suggest that postsynaptic and presynaptic defects occur at the NMJ of larvae expressing mutTARDBP, as could be caused by presynaptic die-back.

\section{Maintenance of locomotor performance in mutTARDBP} following application of $\mathrm{Ca}^{2+}$ channel agonists

A possible mechanism that could account for the deficits at the $\mathrm{NMJ}$ in mutTARDBP larvae is reduced $\mathrm{Ca}^{2+}$ entry during the action potential. At the NMJ in lower vertebrates P/Q-, N-, and L-type voltage-dependent calcium channels (VDCCs) mediate acetylcholine release (Arenson and Evans, 2001; Thaler et al., 2001; Nurullin et al., 2011). We therefore sought to test agonists of these channels for their potential neuroprotective properties. While numerous calcium channel antagonists have been developed, relatively few agonists exist. For P/Q-type VDCCs we tested in an initial set of experiments animals that were chronically 
A
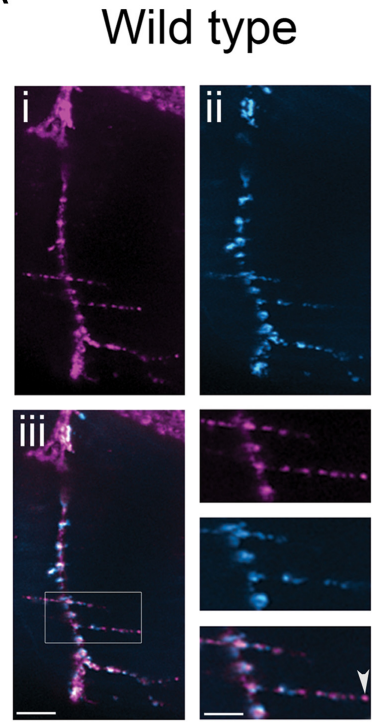

D

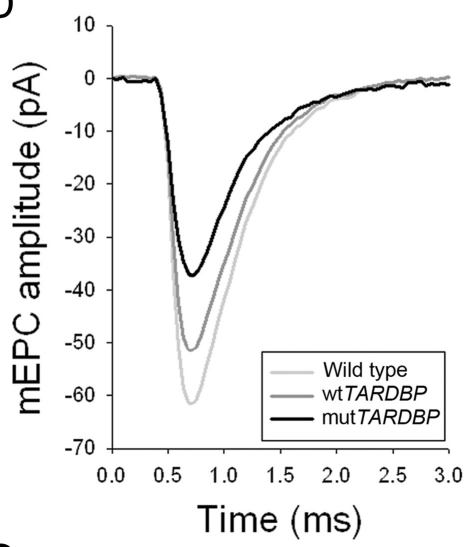

G

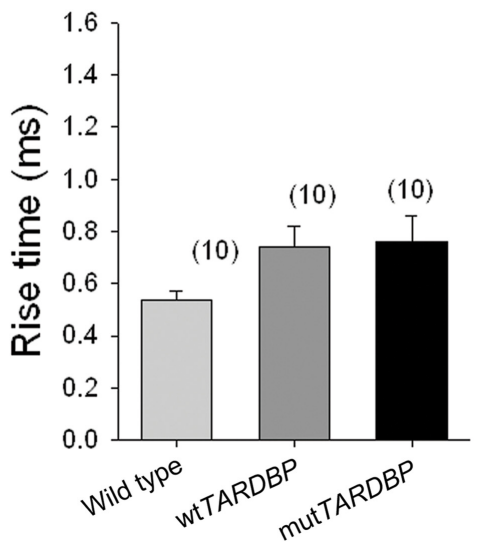

wtTARDBP
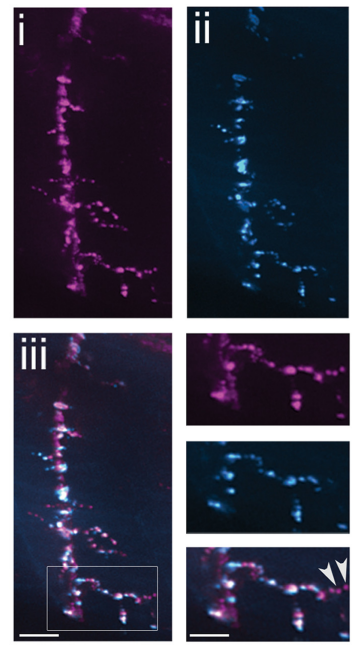

E

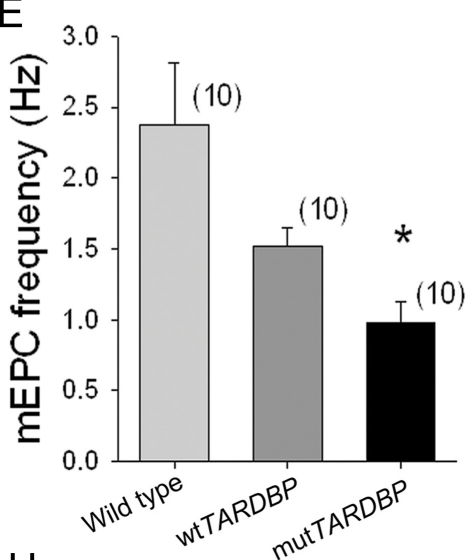

$\mathrm{H}$
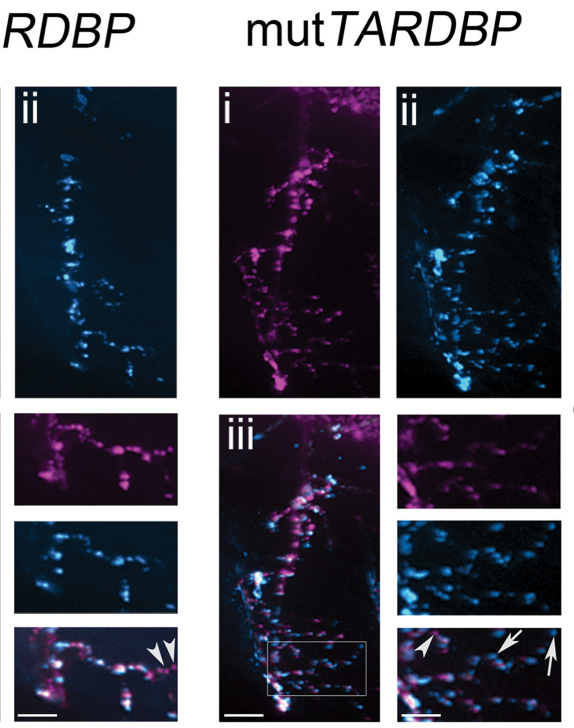

B
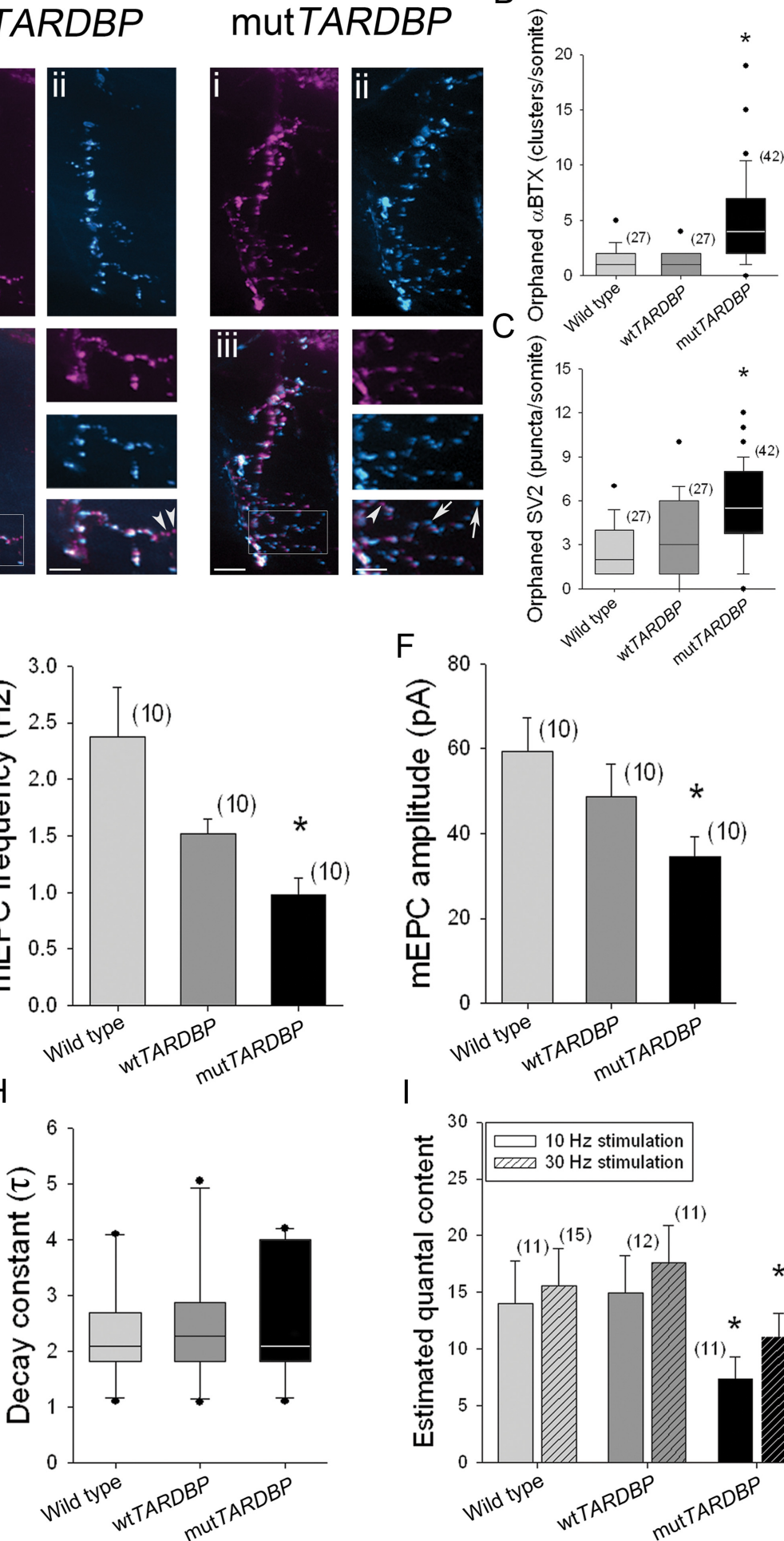

$F$
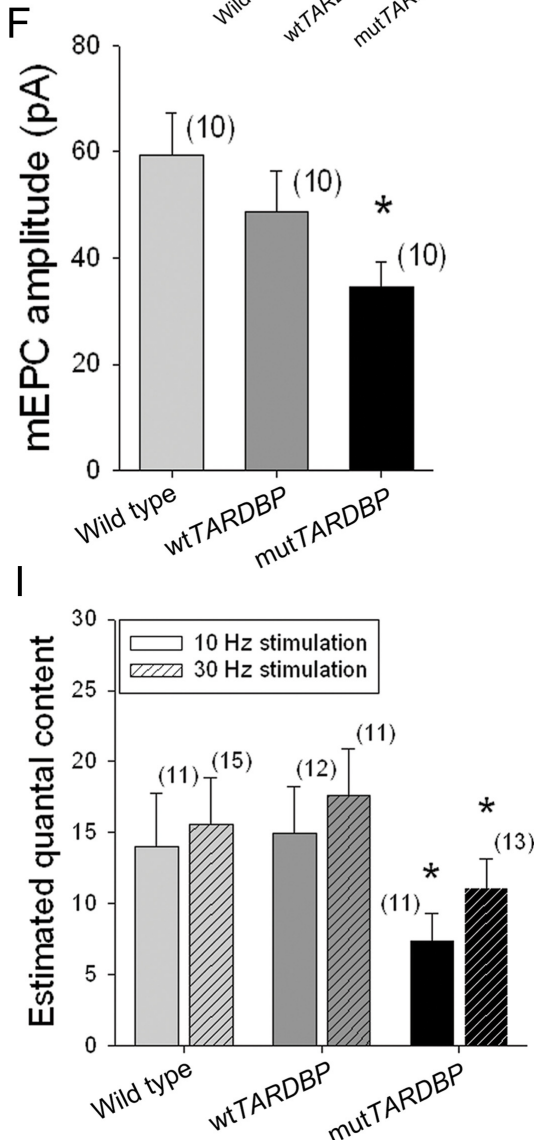

Figure 3. Zebrafish expressing mutTARDBP displayed orphaned presynaptic endings and acetylcholine receptor clusters, attenuated mEPCs, and reduced quantal content. $\boldsymbol{A}$, Representative images of one ventral root projection double labeled for SV2 (presynaptic marker, i) and $\alpha$ BTX (postsynaptic, ii). Wild-type and wtTARDBP larvae showed extensive colocalization of both SV2 and $\alpha$ BTX (iii, merged). However, we observed an increase in the number of orphaned $\alpha$ BTX labeling (arrowheads) and orphaned SV2 labeling (arrows) in mutTARDBP larvae. $B, C$, Recordings of mEPCs, which result from spontaneous release of a quantum, were recorded. $\boldsymbol{D}$, Representative mEPCs. Animals expressing mutTARDBP displayed $\mathrm{mEPCS}$ with reduced frequency $(\boldsymbol{E})$ and reduced amplitudes $(\boldsymbol{F})$, indicating that the numbers of functional synapses are reduced or a proportion are nonfunctional. Kinetics of mEPC was not found to be significantly different. $\mathbf{G}$, Rise time. $\boldsymbol{H}$, Decay constant. $\boldsymbol{I}$, Quantal content measured from paired recordings at 10 and $30 \mathrm{~Hz}$ were calculated by dividing the amplitude of individual EPC by the mean mEPC amplitude. Fish expressing mutTARDBP displayed significantly reduced quantal content from each AP. Numbers in parentheses represent sample sizes. Asterisks represent statistical significant differences from wild-type zebrafish. 
A Water FPL 64176
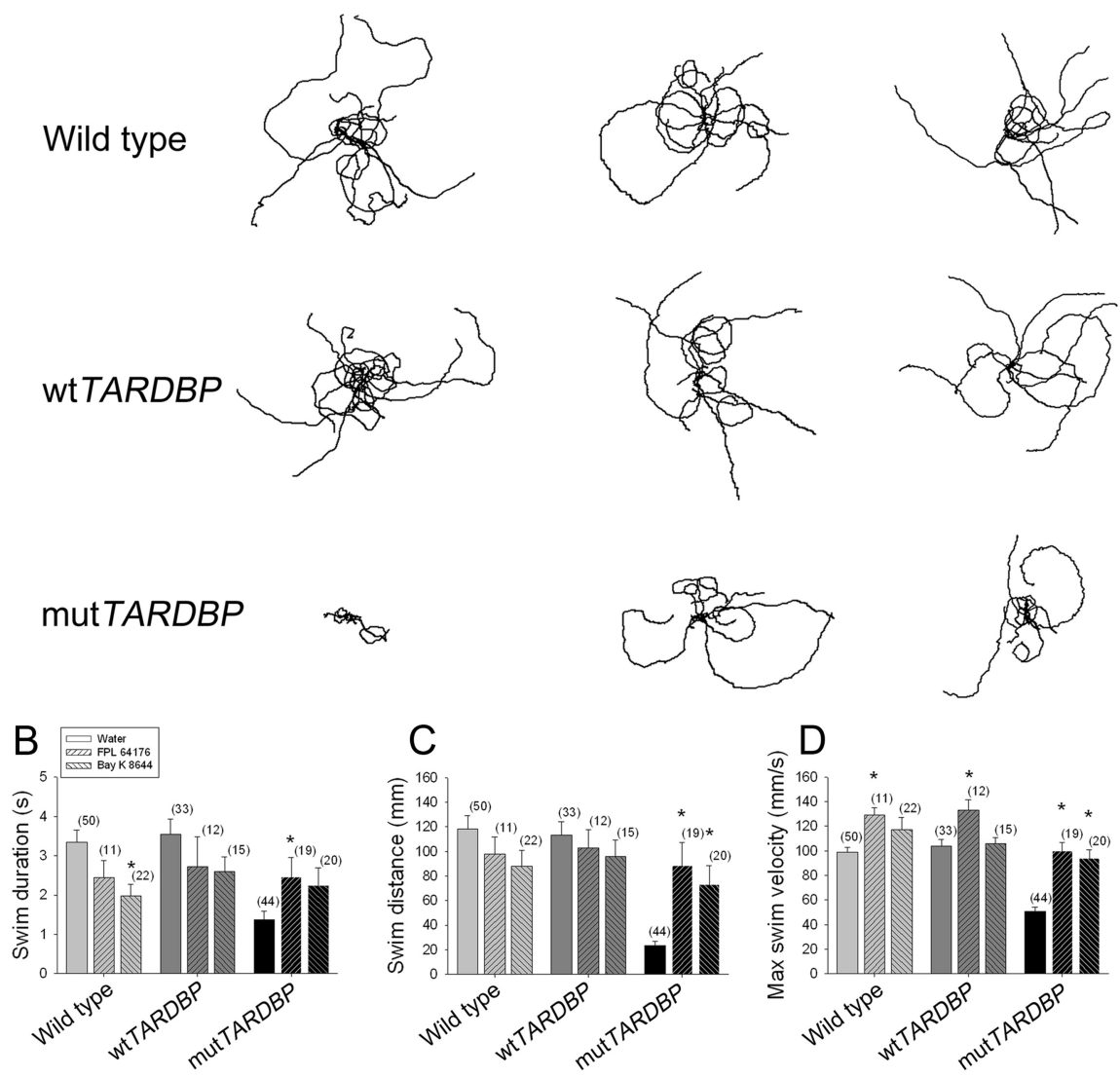

Figure 4. Treatment with the calcium channel agonists FPL 64176 or Bay K 8644 recovers locomotor performance in intact zebrafish expressing mutTARDBP. A, Examples of 10 superimposed locomotor path traces from each treatment group. Swim duration $(\boldsymbol{B})$, swim distance $(\boldsymbol{C})$, and maximum swim velocity $(\boldsymbol{D})$ were tabulated for individual animals. Chronic $(12 \mathrm{~h})$ treatment with $0.1 \mu \mathrm{m}$ FPL 64176 significantly increased swim duration. Swim distance and maximum swim velocity in mutTARDBP larvae were also found to be restored following either $0.1 \mu \mathrm{M} \mathrm{FPL} 64176$ or $1 \mu \mathrm{m}$ Bay K 8644 application. Numbers in parentheses represent sample sizes. Asterisks represent statistical significant differences from fish treated with water within wild-type, wtTARDBP, or mutTARDBP treatment groups $(p<0.05)$.

treated (12 h) with roscovitine (Yan et al., 2002) and then recorded locomotor performance following touch. At low concentrations $(0.1$ and $1 \mu \mathrm{M})$ mutTARDBP-expressing larvae did not display any improvements in swim performance and higher concentrations $(5,10$, and $50 \mu \mathrm{M})$ proved toxic to all larvae.

To potentiate $\mathrm{Ca}^{2+}$ entry via L-type VDCCs we treated animals with the agonist FPL 64176 or Bay K 8644 (Kunze and Rampe, 1992; Carlin et al., 2000). These compounds had no obvious effect on wild-type and wtTARDBP larvae (Fig. 4). Acute (30 min) treatment of a low concentration $(0.1 \mu \mathrm{M})$ of FPL 64176 did not improve locomotor performance; however, at $1 \mu \mathrm{M}$ the swim duration (but not the distance or maximum velocity) increased in mutTARDBP larvae (data not shown). Higher concentrations $(10 \mu \mathrm{M})$ proved toxic. Chronic $(12 \mathrm{~h})$ exposure to $0.1 \mu \mathrm{M}$ FPL 64176 restored swim duration, distance, and maximum swim velocity and $1 \mu \mathrm{M}$ Bay $\mathrm{K} 8644$ restored swim distance and maximum swim velocity in mutTARDBP larvae (Fig. 4). In contrast and as expected, application of $1 \mu \mathrm{M}$ the calcium channel antagonist nifedipine for either $30 \mathrm{~min}$ or $12 \mathrm{~h}$ significantly reduced the swim duration, distance, and maximum velocity in all fish examined (data not shown).

We next examined the possibility that FPL 64176 treatment could increase cell death in the spinal cord. Following $12 \mathrm{~h} 0.1$
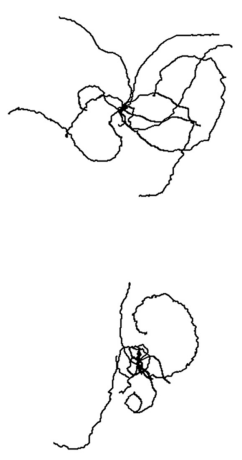

Bay K 8644

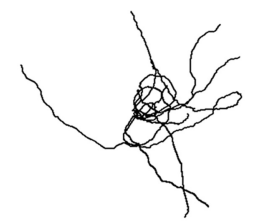

$\mu \mathrm{M}$ FPL 64176 treatment wild-type larvae displayed a mean of $2.6 \pm 0.3(n=24)$, wtTARDBP-expressing larvae displayed $2.9 \pm 0.3(n=21)$, and larvae expressing mutTARDBP displayed $2.3 \pm 0.2(n=21)$ AO positive cells, respectively, and were not found to be different (one-way ANOVA, $p>0.05)$.

\section{Preservation of NMJ transmission in mutTARDBP following application of $\mathrm{Ca}^{2+}$ channel agonists}

We next used paired $\mathrm{CaP}$ motoneuron and fast-twitch muscle recordings to investigate the synaptic mechanisms by which chronic exposure to VDCC agonists might orchestrate locomotor recovery. As with untreated animals, treatment of wild-type larvae and larvae expressing wtTARDBP with $0.1 \mu \mathrm{M} \mathrm{FPL}$ 64176 or $1 \mu \mathrm{M}$ Bay K 8644 for $12 \mathrm{~h}$ did not display any differences in the fidelity of synaptic transmission during $10 \mathrm{~Hz}$ (Fig. $5 A, C, I$ ) or $30 \mathrm{~Hz}$ stimulation (Fig. $5 B, D, I)$. Remarkably though, FPL 64176 (Fig. $5 E, F$ ) or Bay K 8644 (Fig. $5 G, H)$ restored NMJ transmission fidelity in larvae expressing mutTARDBP (Fig. 5I). Moreover, the reduced mean EPC amplitude in animals expressing mutTARDBP was recovered following treatment with either drug (Fig. $5 J$ ) and the variability in EPC amplitude was reduced to normal values (Fig. $5 K$ ). These data indicate that chronically increasing the open probability of VDCCs at a low dose of FPL 61746 or Bay K 8644 restored and stabilized otherwise compromised synaptic transmission at the NMJ in larvae expressing mutTARDBP.

\section{$\mathrm{Ca}^{2+}$ channel agonists stabilize NMJ structure and function in mutTARDBP}

We next examined the anatomical features of the NMJ in zebrafish expressing mutTARDBP following $12 \mathrm{~h}$ treatment with $0.1 \mu \mathrm{M}$ FPL 64176 or $1 \mu \mathrm{M}$ Bay K 8644 to see if the morphology was also preserved. As with the tight colocalization of presynaptic and postsynaptic markers that occurred in wild-type and wtTARDBP larvae (Fig. 4A, C), both FPL 64176 (Fig. 6A-C) and Bay K 8644 (Fig. 6D,E) had no effect on NMJ anatomy in wild-type and wtTARDBP larvae. In addition, both compounds had a protective effect on NMJ anatomy in mutTARDBP larvae as we did not find any significant differences in the number of orphaned $\alpha$ BTX clusters (Fig. $6 A, B, D$ ). There was, however, a slight but significant increase in the number of orphaned presynaptic puncta (Fig. 6A, C) in larvae treated with FPL 64176 but not with Bay K 8644 (Fig. 6E). This suggests that structural abnormalities occurring at the NMJ of zebrafish expressing mutTARDBP could be mostly preserved by chronic treatment with FPL 64176 or Bay $\mathrm{K}$ 8644. We further confirmed this improvement by examining unitary (quantal) events at the NMJs. Analysis of mEPCs did not reveal any differences in the frequency or amplitude of mEPCs 
A

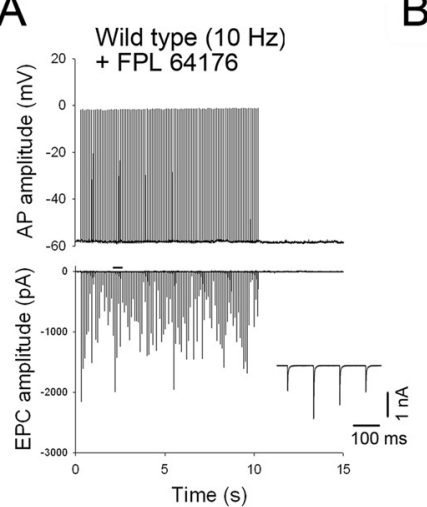

$\mathrm{E}$
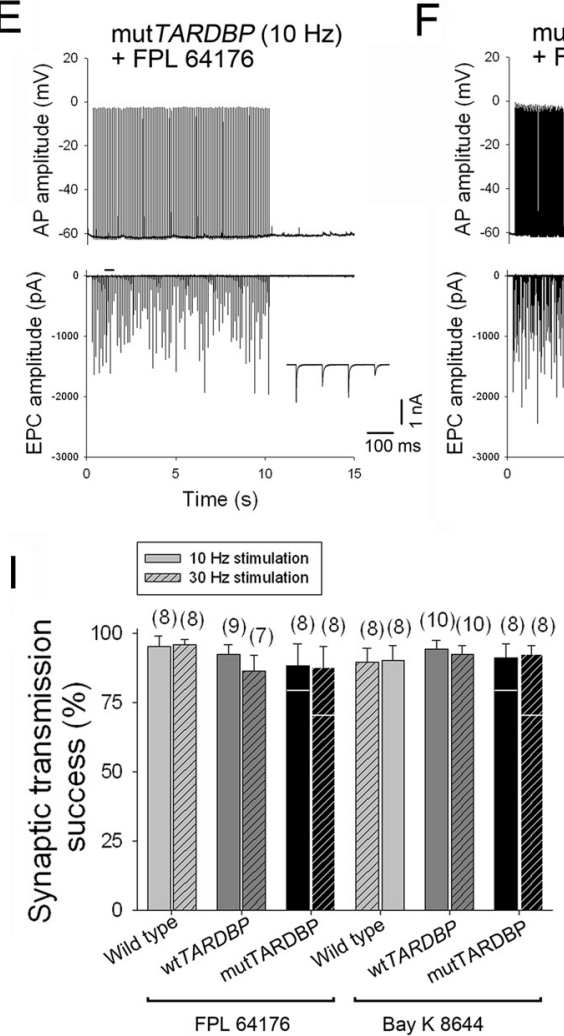

B

F
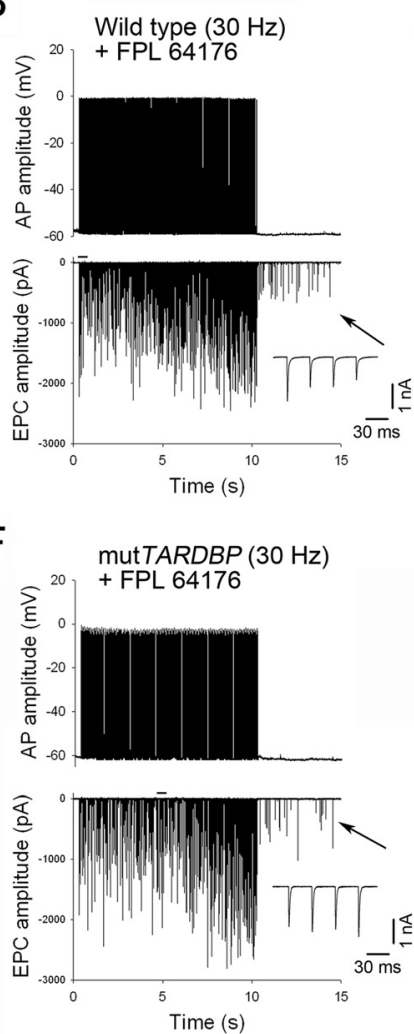

$\mathrm{J}$

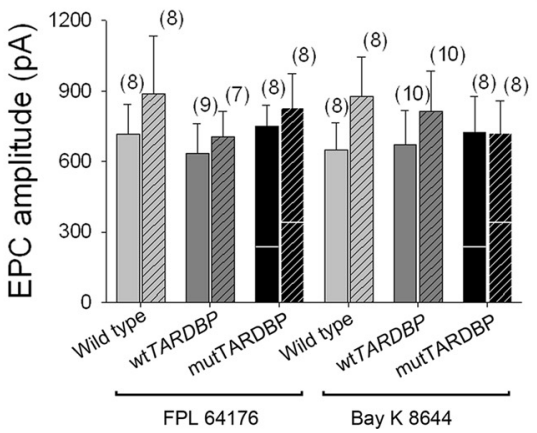

C

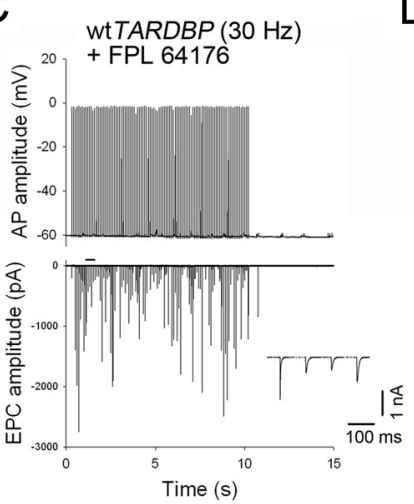

G
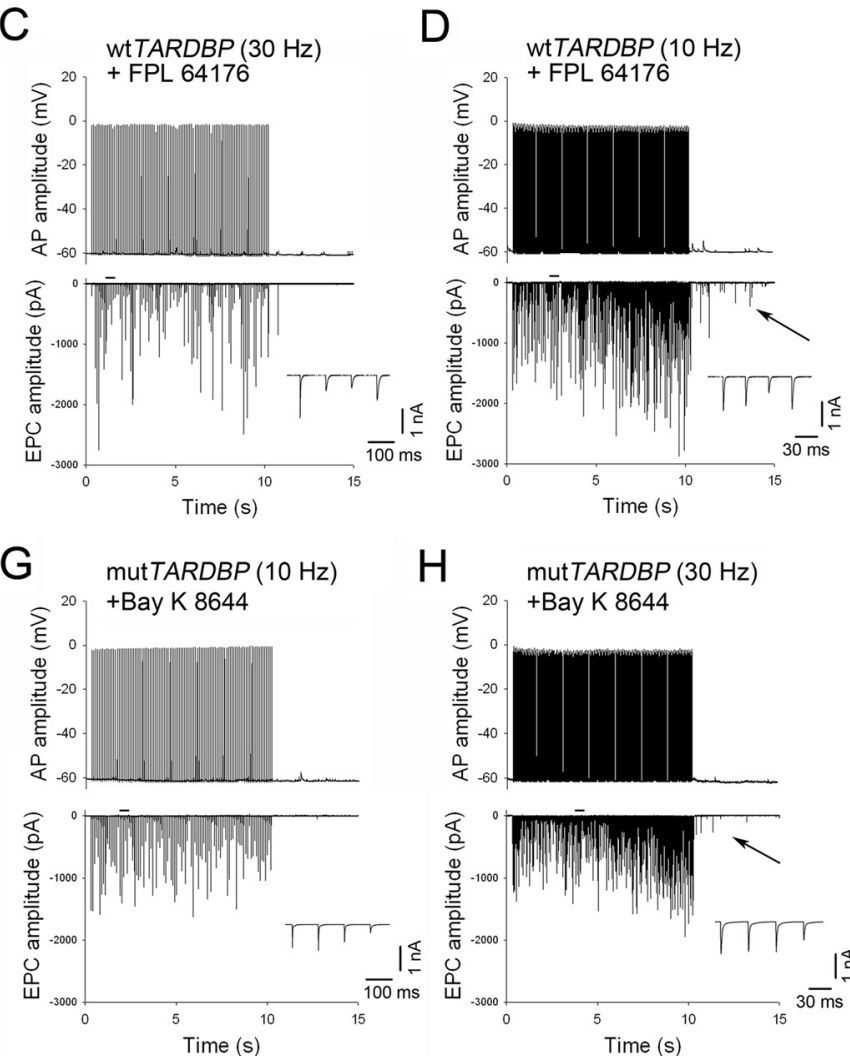

$\mathrm{H}$
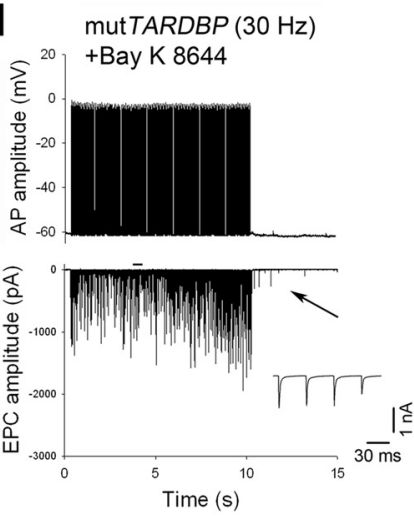

K

Figure 5. Restoration of fidelity of NMJ synaptic transmission and EPC amplitude in zebrafish expressing mutTARDBP and treated with the calcium channel agonists FPL 64176 or Bay K 8644 . Paired (primary motor neuron/muscle) recordings were performed in animals treated chronically ( $12 \mathrm{~h}$ ) with either of these agents. $\boldsymbol{A}, \boldsymbol{B}$, Representative traces of $10 \mathrm{~s}$ trains of 10 and $30 \mathrm{~Hz}$ stimulation. Top traces show evoked action potentials (APs) and the bottom traces show corresponding fast-twitch muscle EPCs in a wild-type larva treated with $0.1 \mu \mathrm{M}$ FPL 64176 . Example traces of APs and corresponding EPCs in a wtTARDBP larva at $30(\boldsymbol{C})$ and $10 \mathrm{~Hz}(\boldsymbol{D})$ and in a mutTARDBP larva at $10(\boldsymbol{E})$ and $30 \mathrm{~Hz}(\boldsymbol{F})$ treated with $0.1 \mu \mathrm{m}$ FPL 64176 . Example traces of evoked EPCs in a mutTARDBP larva at $10(\boldsymbol{G})$ and $30 \mathrm{~Hz}(\boldsymbol{H})$ treated with $1 \mu \mathrm{m}$ Bay K 8644. Arrows in $\boldsymbol{B}, \boldsymbol{D}, \boldsymbol{F}$, and $\boldsymbol{H}$ indicate poststimulus asynchronous events that were not present in untreated larvae expressing mutTARDBP (Fig. $2 \boldsymbol{H}$ ). Insets are enlarged example traces of EPCs in $\boldsymbol{A}-\boldsymbol{H}$. Remarkably, treatment with either FPL 64176 or Bay $\mathrm{K} 8644$ resulted in normal synaptic transmission success rates in fish expressing mutTARDBP $(I)$, and evoked EPCs were large and not found to be significantly different from wild-type larvae or larvae expressing wtTARDBP(J). Finally, we observed no differences in the variability of EPC amplitude suggesting more stable synaptic transmission $(\boldsymbol{K})$. White lines in $\boldsymbol{I}$ and $\boldsymbol{J}$, and black lines in $\boldsymbol{K}$ represent the mean values obtained from fish expressing mutTARDBP and not treated with FPL 64176. Numbers in parentheses represent sample sizes.

occurring in zebrafish expressing wtTARDBP or mutTARDBP and wild-type larvae treated with either $0.1 \mu \mathrm{M}$ FPL 64176 or 1 $\mu \mathrm{M}$ Bay K 8644 for 12 h (Fig. $6 F-J, L$ ). Estimates of quantal content measured in our paired $\mathrm{CaP}$ motoneuron-fast-twitch muscle recordings revealed significant improvements in larvae expressing mutTARDBP when treated chronically with either FPL 64176 or Bay K 8644 (Fig. $6 K, M$ ).

\section{Discussion}

The physiological and functional consequences of mutant TDP-43 expression in ALS remain unknown yet are vitally important for identifying the cause of motoneuron dysfunction in TDP-43-associated ALS cases. The results presented here build upon earlier findings, which indicated that mutTARDBP expression in zebrafish (Kabashi et al., 2010b), drosophila (Wang et al., 2011) and mice (Swarup et al., 2011) is coincident with impairments in locomotor behavior. This was characterized here for zebrafish by showing reductions in the maximum swim velocity and reduced swim distances and durations, despite normal body morphology. We demonstrated that fast-twitch trunk muscles retain normal electrophysiological properties in mutTARDBP larvae, whereas the primary 
A
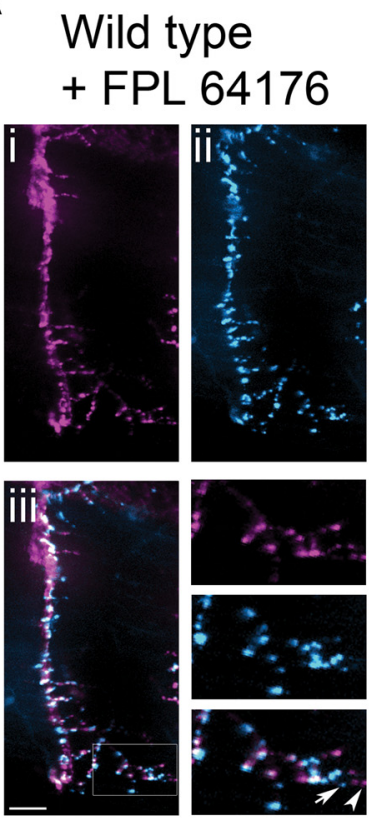

FPL 64176
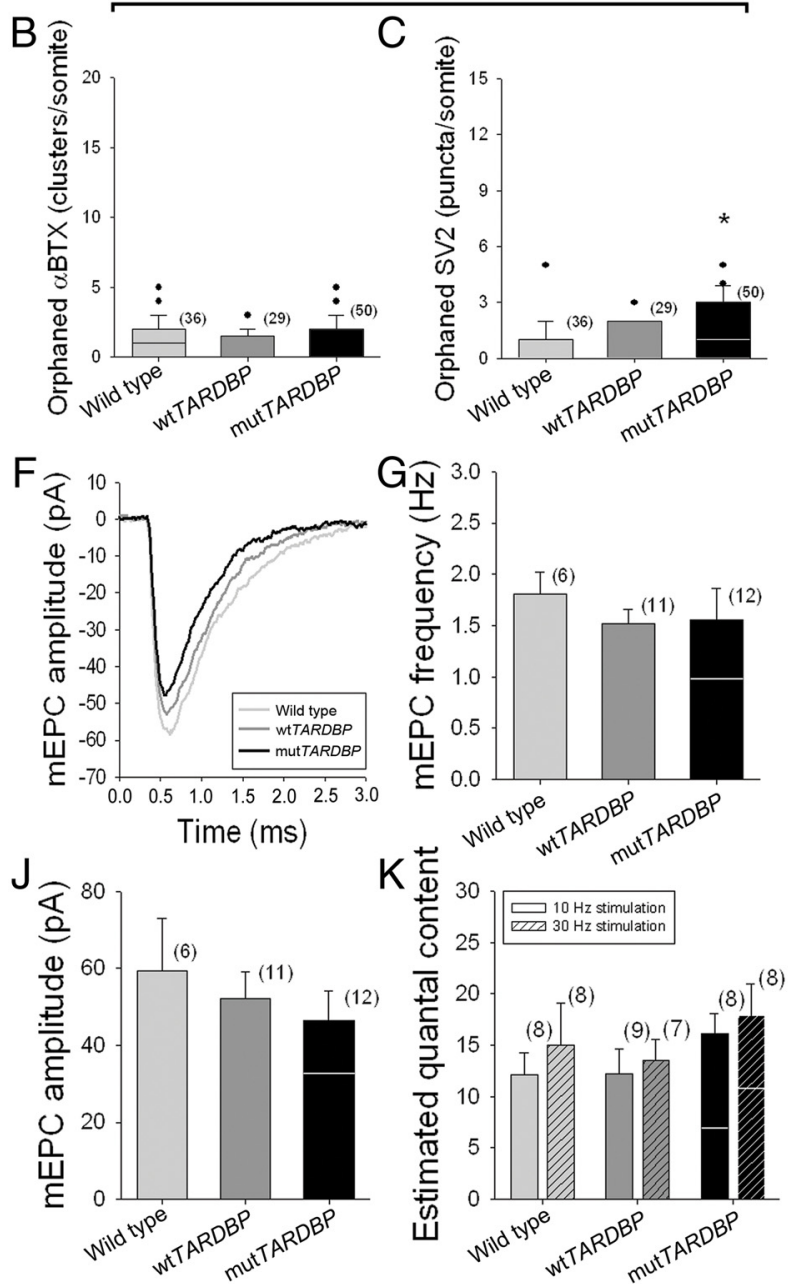

\section{mutTARDBP}

+ FPL 64176
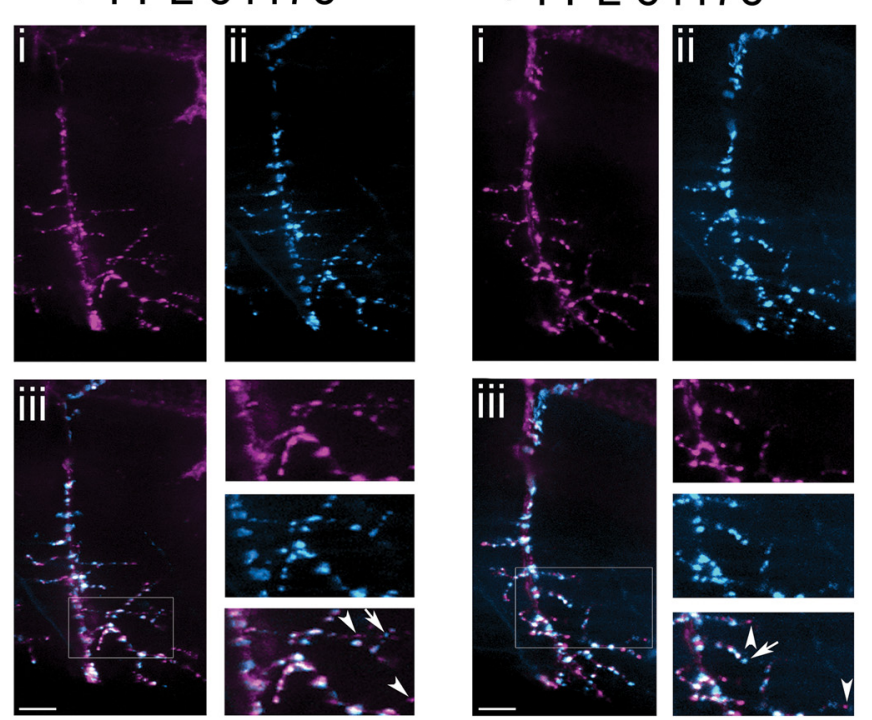

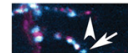

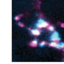

\section{mutTARDBP \\ + Bay K 8644}
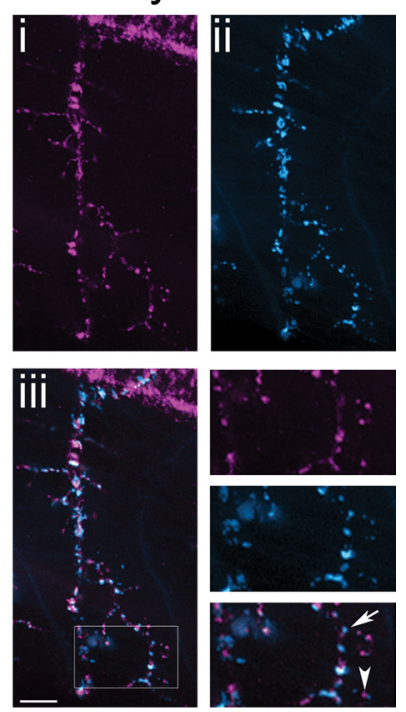

\section{Bay K 8644}
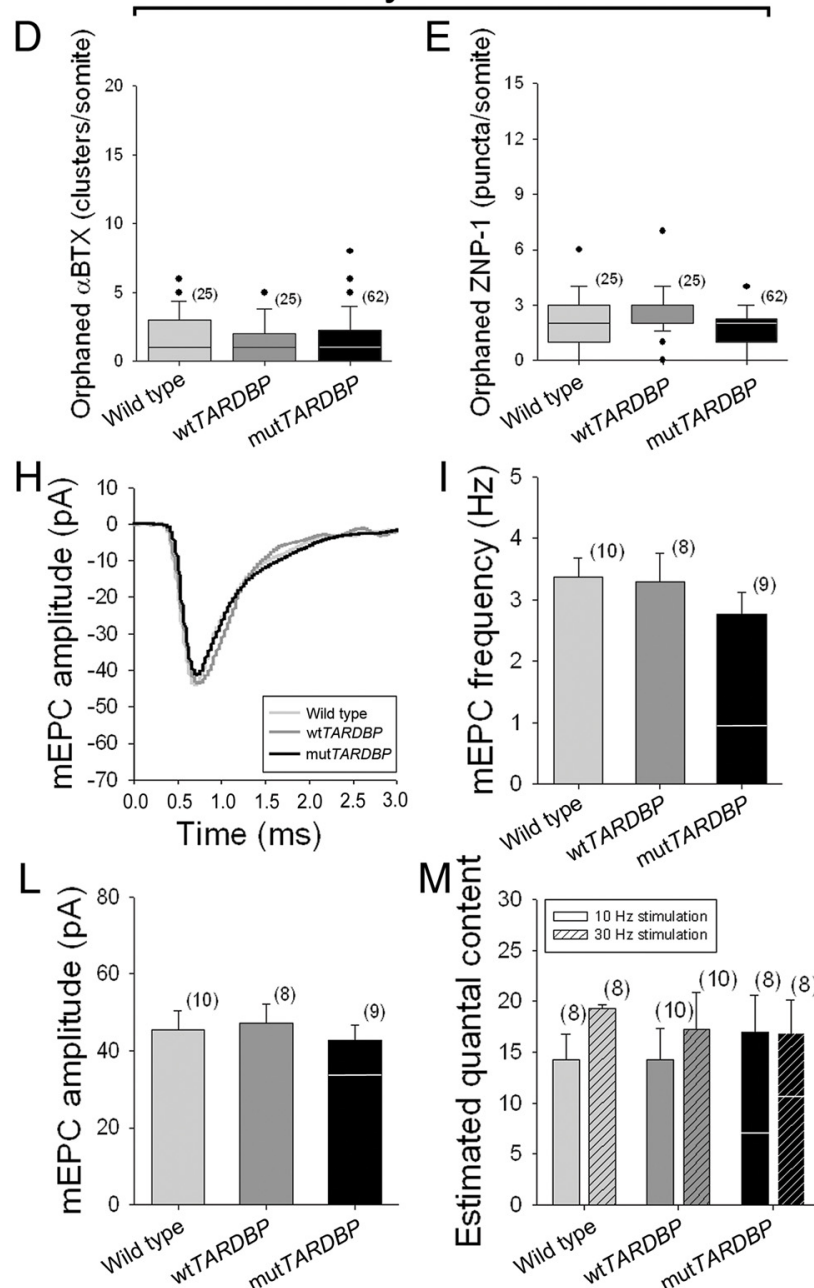

Figure 6. Chronic treatment with FPL 64176 or Bay K 8644 maintains NMJ morphology and function in zebrafish expressing mutTARDBP. $A$, Representative images of one ventral root projection double labeled for SV2 (presynaptic marker, i), $\alpha$ BTX (postsynaptic, ii), and merge (iii) in wild-type, wtTARDBP, and mutTARDBP larvae treated with $0.1 \mu \mathrm{M}$ FPL 64176 for $12 \mathrm{~h}$. ZNP-1 instead of SV2 was used as a presynaptic marker for larvae treated with $1.0 \mu \mathrm{m}$ Bay K8644. Arrowheads and arrows in insets represent orphaned SV2/ZNP-1 puncta and $\alpha$ BTX clusters, respectively. $\boldsymbol{B}-\boldsymbol{E}$, All animals treated either with FPL 64176 or Bay K 8644 displayed a low incidence of orphaned $\alpha$ BTX clusters and SV2/ZNP-1 puncta; however, zebrafish expressing mutTARDBP and treated (Figure legend continues.) 
motoneurons innervating these muscles were more excitable. We also demonstrated an increase in neuronal death in the spinal cord, including ventral cells, which may correspond to motoneurons, of fish expressing mutTARDBP following application of NMDA.

Sustained motoneuron depolarization following application of NMDA has been reported previously in 48 hpf zebrafish (McDearmid and Drapeau, 2006) and this might have exacerbated cell stress in neurons expressing mutTARDBP. A proposed theory for the occurrence of motoneuron degeneration in ALS is an increase in sensitivity to stressful glutamatergic excitation, which leads to neuronal depolarization and excitotoxic cell death (for review, see Shaw and Ince, 1997; Ferraiuolo et al., 2011) and our findings are consistent with this phenomenon. Accordingly riluzole, which stabilizes neural activity and protects against glutamatergic excitotoxicity (Cifra et al., 2011), is currently the only treatment for ALS and extends life by a few months when administered at a symptomatic stage (Bensimon et al., 1994). Clearly much remains to be understood to develop better therapeutics and it may be that earlier, preclinical impairment of NMJ transmission due to lowered calcium entry is an initial limiting factor that compromises the NMJ restoration of which could be beneficial.

The most interesting finding was our observation of impairments in synaptic transmission across the NMJ under physiologically relevant conditions. We observed reduced fidelity of synaptic transmission and attenuated muscle EPCs, which were more variable in size in zebrafish expressing mutTARDBP. Similar observations were made for the periodic failure of action potentials to generate endplate potentials in SOD1 ${ }^{\mathrm{G} 93 \mathrm{~A}}$ mice (Souayah et al., 2012). We further show denervated endplates as reported previously in mutTARDBP rodents (Zhou et al., 2010; Swarup et al., 2011), mutant SOD1 expressing mice (Frey et al., 2000; Fischer et al., 2004) and in tissue from patients with ALS (Maselli et al., 1993). Finally we observed an increase in orphaned terminals and reduced frequencies and amplitudes of unitary events as reported for tissue from patients with ALS (Maselli et al., 1993). Many of these abnormalities thus share common characteristics with ALS pathophysiology.

Despite these abnormalities functional connectivity could be partially recovered following acute or better yet chronic application with the L-type VDCC agonists FPL 64176 or Bay K 8644. Acute application of FPL 64176 restored swim duration though not distance or velocity in mutTARDBP, suggesting that it may have some therapeutic potential at later stages in the progression of the disease. Because acute effects occur at a stage where the NMJ is disrupted, it is possible that FPL 64176 is also having a central effect in prolonging CPG activity. A central effect on interneuron activity would be interesting from the clinical perspective of mutTARDBP implications in frontotemporal lobar

\footnotetext{
$\leftarrow$

(Figure legend continued.) with FPL 64176 did display a slightly high number of orphaned SV2 puncta compared with wild-type zebrafish (C). Representative mEPCs from animals treated with FPL $64176(\boldsymbol{F})$ or Bay K $8644(\boldsymbol{H})$. Importantly, no differences were found in the frequency $(\boldsymbol{G}, \boldsymbol{I})$ and amplitude $(\boldsymbol{J}, \boldsymbol{L})$ of $\mathrm{mEP}(\mathrm{s}$ across treatment groups. $\boldsymbol{K}, \boldsymbol{M}$, Quantal content measured from paired recordings at 10 and $30 \mathrm{~Hz}$ was not found to be significantly different from wildtype, wTTARDBP, or mutTARDBP larvae, implicating that overall function of these NMJs was restored following treatment with FPL 64176 or Bay K 8644 . White lines in $\mathbf{G}, \mathbf{I}, \mathbf{J}, \boldsymbol{K}, \boldsymbol{L}, \boldsymbol{M}$ represent the mean values obtained from fish expressing mutTARDBP and not treated with FPL 64176 or Bay K 8644 . Numbers in parentheses represent sample sizes. Asterisks represent statistical significant difference from wild-type zebrafish in $C$.
}

degeneration with loss of cortical interneurons (Neumann et al., 2006).

The observation that chronic FPL 64176 or Bay K 8644 treatment restored locomotor performance suggests that attenuated calcium entry in the presynaptic terminal plays a substantial role in impairing locomotor function in fish expressing mutTARDBP. In contrast to the coupling to L- and P/Q-type VDCCs at the lower vertebrate NMJ, at the mature mouse NMJ vesicular release is coupled to N- and P/Q-type VDCCs (Katz et al., 1996). Although L-VDCCs are usually found in the dendrites and soma of mature motoneurons (Carlin et al., 2000), they have been identified at the NMJ of immature motoneurons (Gray et al., 1992) and play a role in perineural $\mathrm{Ca}^{2+}$ influx at the mature NMJ (Urbano and Uchitel, 1999). Previous work has demonstrated that depletion of TDP-43 with antisense oligonucleotides in the mouse results in the concomitant downregulation of several genes involved in synaptic transmission, one of which is Cacnalc, which encodes an L-type VDCC (Polymenidou et al., 2011) and is a target of FPL 64176 and Bay K 8644.

Of relevance to ALS, L-type VDCCs are coupled to transmission during re-innervation following nerve crush (Katz et al., 1996) and recovery from botulinum toxin A (Santafé et al., 2000). A similar coupling of L-type VDCC to transmission might thus exist following the process of denervation in ALS. Furthermore, evidence of humoral abnormalities affecting calcium channels has been observed in ALS. L-type VDCC antibodies were identified in the majority of patients with ALS (Smith et al., 1992). The ionophore-forming $\alpha_{1}$-subunit of the L-type VDCC was subsequently demonstrated to bind the antibody (Kimura et al., 1994). Human ALS patient IgG demonstrates immunoreactivity when tested in wild-type mouse diaphragm with effects upon miniature endplate potentials through other VDCCs (Gonzalez et al., 2011).

Regardless of the specific type of calcium channel targeted, our results clearly demonstrate that low concentrations of FPL 64176 or Bay K 8644 restored otherwise compromised synaptic transmission in mutTARDBP expressing larvae, although at high concentrations these compounds were toxic. The preservation of NMJ structure and function and consequent motor activity that was observed following chronic treatment with low concentrations of FPL 64176 or Bay K 8644 suggests that these compounds may be particularly useful at "preclinical" stages of the phenotype. If translatable, drug intervention at these early stages preceding motoneuron death would be the preferred therapeutic window. Our results obtained by transient expression in zebrafish larvae of mutated human genes known to cause ALS must of course be interpreted cautiously. This animal is undergoing rapid development and it is unclear if and how developmental processes interact with degenerative pathways, particularly in the context of late onset disorders.

Although ALS manifests clinically in adulthood, diseaseassociated mutant genes are expressed throughout life and precocious abnormalities do appear. Compelling support for this has been largely gained from the study of mutant SOD1 mice, which revealed that early abnormalities occur both peripherally and centrally in the nervous system (for review, see Murray et al., 2010; Dadon-Nachum et al., 2011; Quinlan, 2011). In their seminal study Fischer et al. (2004) demonstrated that a significant proportion $(40 \%)$ of endplates were denervated by $47 \mathrm{~d}$ while motor deficits ("clinical presentation"), loss of ventral root axons, and loss of $\alpha$ motoneuron cell bodies was not observed until days 78, 80, and 100, respectively (with death occurring at $131 \mathrm{~d}$ ). Early changes occurring at NMJs of SOD1 ${ }^{\text {G93A }}$ mice have been 
noted previously and include selective loss of fast-fatigable NMJ synapses by $50 \mathrm{~d}$ of age (Frey et al., 2000) and loss of motor unit number as early as day 40 (Kennel et al., 1996). Similar behavioral and cellular deficits have been reported for mutant TARDBP rodents (Zhou et al., 2010; Swarup et al., 2011), though a physiological analysis has not been performed. Along with these peripheral anomalies central changes occurring in the dendrites and cell body of motoneurons in SOD1 mice have been documented. In particular, increases in the persistent inward currents carried by $\mathrm{Na}^{+}$and $\mathrm{Ca}^{2+}$ have been described both in cultured motoneurons (Kuo et al., 2005) and motoneurons of the spinal cord (Bories et al., 2007) and are believed to underlie the increases in neuronal hyperexcitability. These reports and the data presented here describing the mutant TDP-43 pathophysiology reinforce the need for developing therapeutics that target preclinical stages of the disease. Targeting the NMJ would have the therapeutic advantage of avoiding issues of blood-brain barrier permeation and could prove useful for the development of preventative therapies.

\section{References}

Arenson MS, Evans SC (2001) Activation of protein kinase C increases acetylcholine release from frog motor nerves by a direct action on L-type $\mathrm{Ca} 2+$ channels and apparently not by depolarisation of the terminal. Neuroscience 104:1157-1164. CrossRef Medline

Bensimon G, Lacomblez L, Meininger V (1994) A controlled trial of riluzole in amyotrophic lateral sclerosis. N Engl J Med 330:585-591. CrossRef Medline

Boon KL, Xiao S, McWhorter ML, Donn T, Wolf-Saxon E, Bohnsack MT, Moens CB, Beattie CE (2009) Zebrafish survival motor neuron mutants exhibit presynaptic neuromuscular junction defects. Hum Mol Genet 18:3615-3625. CrossRef Medline

Bories C, Amendola J, Lamotte d'Incamps B, Durand J (2007) Early electrophysiological abnormalities in lumbar motoneurons in a transgenic mouse model of amyotrophic lateral sclerosis. Eur J Neurosci 25:451459. CrossRef Medline

Buss RR, Drapeau P (2001) Synaptic drive to motoneurons during fictive swimming in the developing zebrafish. J Neurophysiol 86:197-210. Medline

Buss RR, Drapeau P (2002) Activation of embryonic red and white muscle fibers during fictive swimming in the developing zebrafish. J Neurophysiol 87:1244-1251. Medline

Carlin KP, Jiang Z, Brownstone RM (2000) Characterization of calcium currents in functionally mature mouse spinal motoneurons. Eur J Neurosci 12:1624-1634. CrossRef Medline

Cifra A, Nani F, Nistri A (2011) Riluzole is a potent drug to protect neonatal rat hypoglossal motoneurons in vitro from excitotoxicity due to glutamate uptake block. Eur J Neurosci 33:899-913. CrossRef Medline

Dadon-Nachum M, Melamed E, Offen D (2011) The "dying-back" phenomenon of motor neurons in ALS. J Mol Neurosci 43:470-477. CrossRef Medline

Ferraiuolo L, Kirby J, Grierson AJ, Sendtner M, Shaw PJ (2011) Molecular pathways of motor neuron injury in amyotrophic lateral sclerosis. Nat Rev Neurol 7:616-630. CrossRef Medline

Fischer LR, Culver DG, Tennant P, Davis AA, Wang M, Castellano-Sanchez A, Khan J, Polak MA, Glass JD (2004) Amyotrophic lateral sclerosis is a distal axonopathy: evidence in mice and man. Exp Neurol 185:232-240. CrossRef Medline

Frey D, Schneider C, Xu L, Borg J, Spooren W, Caroni P (2000) Early and selective loss of neuromuscular synapse subtypes with low sprouting competence in motoneuron diseases. J Neurosci 20:2534-2542. Medline

Gonzalez LE, Kotler ML, Vattino LG, Conti E, Reisin RC, Mulatz KJ, Snutch TP, Uchitel OD (2011) Amyotrophic lateral sclerosis-immunoglobulins selectively interact with neuromuscular junctions expressing P/Q-type calcium channels. J Neurochem 119:826-838. CrossRef Medline

Gray DB, Brusés JL, Pilar GR (1992) Developmental switch in the pharmacology of $\mathrm{Ca}^{2+}$ channels coupled to acetylcholine release. Neuron 8:715724. CrossRef Medline

Kabashi E, Valdmanis PN, Dion P, Spiegelman D, McConkey BJ, Vande
Velde C, Bouchard JP, Lacomblez L, Pochigaeva K, Salachas F, Pradat PF, Camu W, Meininger V, Dupre N, Rouleau GA (2008) TARDBP mutations in individuals with sporadic and familial amyotrophic lateral sclerosis. Nat Genet 40:572-574. CrossRef Medline

Kabashi E, Champagne N, Brustein E, Drapeau P (2010a) In the swim of things: recent insights to neurogenetic disorders from zebrafish. Trends Genet 26:373-381. CrossRef Medline

Kabashi E, Lin L, Tradewell ML, Dion PA, Bercier V, Bourgouin P, Rochefort D, Bel Hadj S, Durham HD, Vande Velde C, Rouleau GA, Drapeau P (2010b) Gain and loss of function of ALS-related mutations of TARDBP (TDP-43) cause motor deficits in vivo. Hum Mol Genet 19:671-683. CrossRef Medline

Kabashi E, Bercier V, Lissouba A, Liao M, Brustein E, Rouleau GA, Drapeau P (2011) FUS and TARDBP but not SOD1 interact in genetic models of amyotrophic lateral sclerosis. PLoS Genet 7:e1002214. CrossRef Medline

Katz E, Ferro PA, Weisz G, Uchitel OD (1996) Calcium channels involved in synaptic transmission at the mature and regenerating mouse neuromuscular junction. J Physiol 497:687-697. Medline

Kennel PF, Finiels F, Revah F, Mallet J (1996) Neuromuscular function impairment is not caused by motor neurone loss in FALS mice: an electromyographic study. Neuroreport 7:1427-1431. CrossRef Medline

Kimmel CB, Ballard WW, Kimmel SR, Ullmann B, Schilling TF (1995) Stages of embryonic development of the zebrafish. Dev Dyn 203:253-310. CrossRef Medline

Kimura F, Smith RG, Delbono O, Nyormoi O, Schneider T, Nastainczyk W, Hofmann F, Stefani E, Appel SH (1994) Amyotrophic lateral sclerosis patient antibodies label Ca2+ channel alpha 1 subunit. Ann Neurol 35: 164-171. CrossRef Medline

Kunze DL, Rampe D (1992) Characterization of the effects of a new $\mathrm{Ca}^{2+}$ channel activator, FPL 64176, in GH3 cells. Mol Pharmacol 42:666-670. Medline

Kuo JJ, Siddique T, Fu R, Heckman CJ (2005) Increased persistent $\mathrm{Na}^{+}$ current and its effect on excitability in motoneurones cultured from mutant SOD1 mice. J Physiol 563:843-854. CrossRef Medline

Kwiatkowski TJ Jr, Bosco DA, Leclerc AL, Tamrazian E, Vanderburg CR, Russ C, Davis A, Gilchrist J, Kasarskis EJ, Munsat T, Valdmanis P, Rouleau GA, Hosler BA, Cortelli P, de Jong PJ, Yoshinaga Y, Haines JL, Pericak-Vance MA, Yan J, et al. (2009) Mutations in the FUS/TLS Gene on chromosome 16 cause familial amyotrophic lateral sclerosis. Science 323:12051208. CrossRef Medline

Lemmens R, Van Hoecke A, Hersmus N, Geelen V, D'Hollander I, Thijs V, Van Den Bosch L, Carmeliet P, Robberecht W (2007) Overexpression of mutant superoxide dismutase 1 causes a motor axonopathy in the zebrafish. Hum Mol Genet 16:2359-2365. CrossRef Medline

Maselli RA, Wollman RL, Leung C, Distad B, Palombi S, Richman DP, Salazar-Grueso EF, Roos RP (1993) Neuromuscular transmission in amyotrophic lateral sclerosis. Muscle Nerve 16:1193-1203. CrossRef Medline

McDearmid JR, Drapeau P (2006) Rhythmic motor activity evoked by NMDA in the spinal zebrafish larva. J Neurophysiol 95:401-417. Medline

Murray LM, Talbot K, Gillingwater TH (2010) Review: neuromuscular synaptic vulnerability in motor neurone disease: amyotrophic lateral sclerosis and spinal muscular atrophy. Neuropathol Appl Neurobiol 36: 133-156. CrossRef Medline

Neumann M, Sampathu DM, Kwong LK, Truax AC, Micsenyi MC, Chou TT, Bruce J, Schuck T, Grossman M, Clark CM, McCluskey LF, Miller BL, Masliah E, Mackenzie IR, Feldman H, Feiden W, Kretzschmar HA, Trojanowski JQ, Lee VM (2006) Ubiquitinated TDP-43 in frontotemporal lobar degeneration and amyotrophic lateral sclerosis. Science 314:130 133. CrossRef Medline

Nurullin LF, Mukhitov AR, Tsentsevytsky AN, Petrova NV, Samigullin DV, Malomouzh AI, Bukharaeva EA, Vyskočil F, Nikolsky EE (2011) Voltage-dependent P/Q-type calcium channels at the frog neuromuscular junction. Physiol Res 60:815-823. Medline

Pasinelli P, Brown RH (2006) Molecular biology of amyotrophic lateral sclerosis: insights from genetics. Nat Rev Neurosci 7:710-723. CrossRef Medline

Polymenidou M, Lagier-Tourenne C, Hutt KR, Huelga SC, Moran J, Liang TY, Ling SC, Sun E, Wancewicz E, Mazur C, Kordasiewicz H, Sedaghat Y, Donohue JP, Shiue L, Bennett CF, Yeo GW, Cleveland DW (2011) Long pre-mRNA depletion and RNA missplicing contribute to neuronal vul- 
nerability from loss of TDP-43. Nat Neurosci 14:459-468. CrossRef Medline

Quinlan KA (2011) Links between electrophysiological and molecular pathology of amyotrophic lateral sclerosis. Integr Comp Biol 51:913-925. CrossRef Medline

Ramesh T, Lyon AN, Pineda RH, Wang C, Janssen PM, Canan BD, Burghes AH, Beattie CE (2010) A genetic model of amyotrophic lateral sclerosis in zebrafish displays phenotypic hallmarks of motoneuron disease. Dis Model Mech 3:652-662. CrossRef Medline

Santafé MM, Urbano FJ, Lanuza MA, Uchitel OD (2000) Multiple types of calcium channels mediate transmitter release during functional recovery of botulinum toxin type A-poisoned mouse motor nerve terminals. Neuroscience 95:227-234. CrossRef Medline

Shaw PJ, Ince PG (1997) Glutamate, excitotoxicity and amyotrophic lateral sclerosis. J Neurol 244 [Suppl 2]:S3-S14. CrossRef Medline

Smith RG, Hamilton S, Hofmann F, Schneider T, Nastainczyk W, Birnbaumer L, Stefani E, Appel SH (1992) Serum antibodies to L-type calcium channels in patients with amyotrophic lateral sclerosis. N Engl J Med 327:1721-1728. CrossRef Medline

Souayah N, Coakley KM, Chen R, Ende N, McArdle JJ (2012) Defective neuromuscular transmission in the SOD $1^{\mathrm{G} 93 \mathrm{~A}}$ transgenic mouse improves after administration of human umbilical cord blood cells. Stem Cell Rev 8:224-228. CrossRef Medline

Sreedharan J, Blair IP, Tripathi VB, Hu X, Vance C, Rogelj B, Ackerley S, Durnall JC, Williams KL, Buratti E, Baralle F, de Belleroche J, Mitchell JD, Leigh PN, Al-Chalabi A, Miller CC, Nicholson G, Shaw CE (2008) TDP-43 mutations in familial and sporadic amyotrophic lateral sclerosis. Science 319:1668-1672. CrossRef Medline

Swarup V, Phaneuf D, Bareil C, Robertson J, Rouleau GA, Kriz J, Julien JP (2011) Pathological hallmarks of amyotrophic lateral sclerosis/frontotemporal lobar degeneration in transgenic mice produced with TDP-43 genomic fragments. Brain 134:2610-2626. CrossRef Medline
Thaler C, Li W, Brehm P (2001) Calcium channel isoforms underlying synaptic transmission at embryonic Xenopus neuromuscular junctions. J Neurosci 21:412-422. Medline

Urbano FJ, Uchitel OD (1999) L-Type calcium channels unmasked by cellpermeant $\mathrm{Ca}^{2+}$ buffer at mouse motor nerve terminals. Pflügers Arch 437:523-528. CrossRef Medline

Vance C, Rogelj B, Hortobágyi T, De Vos KJ, Nishimura AL, Sreedharan J, Hu X, Smith B, Ruddy D, Wright P, Ganesalingam J, Williams KL, Tripathi V, Al-Saraj S, Al-Chalabi A, Leigh PN, Blair IP, Nicholson G, de Belleroche J, Gallo JM, et al. (2009) Mutations in FUS, an RNA processing protein, cause familial amyotrophic lateral sclerosis type 6 . Science 323:1208-1211. CrossRef Medline

Wang JW, Brent JR, Tomlinson A, Shneider NA, McCabe BD (2011) The ALS-associated proteins FUS and TDP-43 function together to affect Drosophila locomotion and life span. J Clin Invest 121:4118-4126. CrossRef Medline

Wen H, Brehm P (2005) Paired motor neuron-muscle recordings in zebrafish test the receptor blockade model for shaping synaptic current. J Neurosci 25:8104-8111. CrossRef Medline

Westerfield M (1995) The zebrafish book: a guide for the laboratory use of zebrafish (Danio rerio), Ed 3. Eugene, OR: University of Oregon.

Westerfield M, McMurray JV, Eisen JS (1986) Identified motoneurons and their innervation of axial muscles in the zebrafish. J Neurosci 6:22672277. Medline

Yan Z, Chi P, Bibb JA, Ryan TA, Greengard P (2002) Roscovitine: a novel regulator of P/Q-type calcium channels and transmitter release in central neurons. J Physiol 540:761-770. CrossRef Medline

Zhou H, Huang C, Chen H, Wang D, Landel CP, Xia PY, Bowser R, Liu YJ, Xia XG (2010) Transgenic rat model of neurodegeneration caused by mutation in the TDP gene. PLoS Genet 6:e1000887. CrossRef Medline 